\title{
Securitized Banking and the Run on Repo
}

\author{
Gary Gorton \\ Yale and NBER \\ Andrew Metrick \\ Yale and NBER
}

First version: January 22, 2009

This version: November 9, 2010

\begin{abstract}
The Panic of 2007-2008 was a run on the sale and repurchase market (the "repo" market), which is a very large, short-term market that provides financing for a wide range of securitization activities and financial institutions. Repo transactions are collateralized, frequently with securitized bonds. We refer to the combination of securitization plus repo finance as "securitized banking", and argue that these activities were at the nexus of the crisis. We use a novel data set that includes credit spreads for hundreds of securitized bonds to trace the path of crisis from subprime-housing related assets into markets that had no connection to housing. We find that changes in the "LIB-OIS" spread, a proxy for counterparty risk, were strongly correlated with changes in credit spreads and repo rates for securitized bonds. These changes implied higher uncertainty about bank solvency and lower values for repo collateral. Concerns about the liquidity of markets for the bonds used as collateral led to increases in repo "haircuts": the amount of collateral required for any given transaction. With declining asset values and increasing haircuts, the U.S. banking system was effectively insolvent for the first time since the Great Depression.
\end{abstract}

*We thank Lei Xie for research assistance, Sara Dowling for editorial assistance, numerous anonymous traders and bankers for help with data, and seminar participants at the NBER Crisis Conference, NY Fed, the Board of Governors of the Federal Reserve System, Texas, MIT, Harvard, LSE, the ASSA Meetings, the European Central Bank, the International Monetary Fund, the National Association of Business Economists, the Brookings Institution, the Santa Fe Institute, Fidelity, State Street, Wellington Capital Management, and the Moody's/Stern Credit Conference for comments. Also, thanks to Charles Calomiris, Yingmei Cheng, Kent Daniel, Chifu Huang, Kevin James, Manfred Kremer, Greg Nini, Richard Rosen, and Jeremy Stein for comments and suggestions. We thank Krista Schwartz for sharing her data with us. We also thank the anonymous referee. Finally, thanks to all those who emailed comments and suggestions. 
The 2007-2008 financial crisis was a system-wide bank run. What makes this bank run special is that it did not occur in the traditional-banking system, but instead took place in the "securitized-banking" system. A traditional-banking run is driven by the withdrawal of deposits, while a securitized-banking run is driven by the withdrawal of repurchase ("repo") agreements. Hence, we describe the crisis as a "run on repo". The purpose of this paper is to propose a mechanism for this new kind of bank run, and to provide supporting evidence for this mechanism through analysis of two novel data sets.

Traditional banking is the business of making and holding loans, with insured demand deposits as the main source of funds. Securitized banking is the business of packaging and reselling loans, with repo agreements as the main source of funds. Securitized-banking activities were central to the operations of firms formerly known as "investment banks" (e.g. Bear Stearns, Lehman Brothers, Morgan Stanley, Merrill Lynch), but they also play a role at commercial banks, as a supplement to traditional-banking activities of firms like Citigroup, J.P. Morgan, and Bank of America. ${ }^{1}$

We argue that the financial crisis that began in August 2007 was a "systemic event," defined in this paper to mean that the banking sector became insolvent, in the sense that it could not pay off its debt. What happened is analogous to the banking panics of the $19^{\text {th }}$ century in which depositors en masse went to their banks seeking to withdraw cash in exchange for demand and savings deposits. The banking system could not honor these demands because the cash had been lent out and the loans were illiquid, so instead they suspended convertibility and relied on clearinghouses to issue certificates as makeshift currency. ${ }^{2}$ Evidence of the insolvency of the banking system (i.e., that the system cannot pay off the demand deposits, as demanded by depositors) in these earlier episodes is the discount on these certificates. We argue that the current crisis is similar in that contagion led to "withdrawals" in the form of unprecedented high repo haircuts and even the cessation of repo lending on many forms of collateral. Evidence of

\footnotetext{
${ }^{1}$ We have chosen a new term, "securitized banking", to emphasize the role of the securitization process both as the main intermediation activity and as a crucial source of the collateral used to raise funds in repo transactions. Other banking terms - "wholesale banking", "shadow banking", or "investment banking" - have broader connotations and do not completely encompass our definition of securitized banking. The closest notion to our definition of securitized banking is the model of "unstable banking" proposed by Shleifer and Vishny (2009).

${ }^{2}$ The clearinghouse private money was a claim on the coalition of banks, rather than a liability of any individual bank. By broadening the backing for the claim, the clearinghouse made the claim safer, a kind of insurance. Gorton (1985) and Gorton and Mullineaux (1987) discuss the clearinghouse response to panics. Also, see Gorton and Huang (2006).
} 
insolvency in 2008 is the bankruptcy or forced rescue of several large firms, with other (even larger) firms requiring government support to stay in business.

To perform our analysis, we use two novel data sets, one with information on 392 securitized bonds and related assets, including many classes of asset-backed securities (ABS), collateralizeddebt obligations (CDOs), credit-default swaps (CDS); the other data set contains repo rates, and repo haircuts. ${ }^{3}$ Using these data, we are able to provide a new perspective on the contagion in this crisis. In our exposition, we use this term "contagion" specifically to mean the spread of the crisis from subprime-housing assets to non-subprime assets that have no direct connection to the housing market. In fact, we argue that to explain the crisis requires explaining why the spreads on non-subprime related asset classes rose dramatically.

To provide background for our analysis, we illustrate the differences between traditional banking and securitized banking in Figures 1 and 2. Figure 1 provides the classic picture of the financial intermediation of mortgages by the traditional-banking system. In Step A, depositors transfer money to the bank, in return for a checking or savings account that can be withdrawn at any time. In Step B, the bank loans these funds to a borrower, who promises to repay through a mortgage on the property. The bank then holds this mortgage on its balance sheet, along with other non-mortgage loans made to retail and commercial borrowers.

Traditional-banking runs, for the most part, were ended in United States after the Great Depression, owing to a combination of influences, including enhanced discount-window lending by the Federal Reserve and the introduction of deposit insurance. Deposit insurance removes any incentive for insured depositors to withdraw their funds, but larger insured banks cannot offer insured depositors to non-retail depositors (including sovereign wealth funds, mutual funds, and cash-rich companies). One solution to this problem is the securitized-banking system illustrated in Figure 2, which takes large "deposits" from investors (Step 1), and then intermediates these deposits to mortgage borrowers (Steps 2 and 3 ) and other debtors.

Step 1 in Figure 2 is an analogue to Step A from Figure 1, but there is one important difference. In the traditional-banking system shown in Figure 1, the deposits are insured by the government. To achieve similar protection in Step 1 of Figure 2, the investor receives collateral from the bank. In practice, this deposit-collateral transaction takes the form of a repo agreement:

\footnotetext{
${ }^{3}$ This paper uses many terms and abbreviations that are atypical or new to the academic literature. Beginning in Section I, the first appearance of these terms is given in bold type, and definitions of bolded terms are given in Appendix A.
} 
the investor "buys" some asset (i.e., the collateral) from the bank for $\$ X$, and the bank agrees to repurchase the same asset some time later (perhaps the next day) for $\$ Y$. The percentage (Y$\mathrm{X}) / \mathrm{X}$ is the "repo rate", and is analogous to the interest rate on a bank deposit. Typically, the total amount of the deposit will be some amount less than the value of the underlying asset, with the difference called a "haircut". For example, if an asset has a market value of $\$ 100$ and a bank sells it for $\$ 80$ with an agreement to repurchase it for $\$ 88$, then we would say that the repo rate is 10 percent $(=88-80 / 80)$, and the haircut is 20 percent $(100-80 / 100)$. If the bank defaults on the promise to repurchase the collateral, then the investor has the right to terminate the agreement and keep or sell the collateral.

Turning next to the lower right corner of Figure 2, we show how the second part of the intermediation differs from traditional banking. In Figure 1, the bank did the work of underwriting the loan itself. In Figure 2, the bank outsources this function to a direct lender. Such lenders grew to prominence in the most recent housing boom, with a specialization of underwriting loans to be held for only a short time before being sold to banks. Much has been written about potential conflicts in this separation of the loan decision from the source of finance, but that is not our topic here. In principle, there is no reason that this separation must necessarily lead to poor underwriting, and in any event such problems do not imply anything about contagion or systemic events.

Another key component of securitized banking is in the "securitization" itself: the intermediation activities that transfer most of the mortgage loans to outside investors in Step 4. We will discuss this step in detail in Section I of the paper. For our purposes here, the key idea is that the outputs of this securitization are often used as collateral in Step 1, so that securitized banking is a cycle that requires all steps to keep running. In this paper, we will show how this cycle broke down in the crisis.

Figure 3 summarizes the relationships between the main elements of traditional and securitized banking. The left column lists the familiar elements of traditional banking: reserves, deposit insurance, interest rates on deposits, and the holding of loans on balance sheet. Bank solvency is promoted by requiring a fraction of deposits to be held in reserve, and in emergencies these reserves can be replenished by borrowing from the central bank. The analogue in securitized banking is the repo haircut, which forces banks to keep some fraction of their assets in reserve when they borrow money through repo markets. The next row, deposit insurance, is a 
promise made by the government to pay depositors in the event of default. The analogue in securitized banking is collateral. Next, a bank in need of cash can raise deposit rates to attract it; the analogues for securitized banking are the repo rates. Finally, the cash raised in traditional banking is lent out, with the resulting loans held on the balance sheet. In securitized banking, funds are lent only temporarily, with loans repackaged and resold as securitized bonds. Some of these bonds are also used as collateral to raise more funds, which completes the cycle.

The "run on repo" can be seen in Figure 4, which plots a "haircut index" from 2007 to 2008. The details of this index will be explained below in Section III; for now, just think of the index as an average haircut for collateral used in repo transactions, not including U.S. treasury securities. This index rises from zero in early 2007 to nearly 50 percent at the peak of the crisis in late 2008. During this time period, several classes of assets stopped entirely from being used as collateral, an unprecedented event that is equivalent to a haircut of 100 percent.

To see how the increase in haircuts can drive the banking system to insolvency, take as a benchmark a repo market size of, for example, $\$ 10$ trillion. With zero haircuts, this is the amount of financing that banks can achieve in the repo markets. When the weighted-average haircut reaches, say, 20 percent, then banks have a shortage of $\$ 2$ trillion. In the crisis, some of this amount was raised early on by issuing new securities. But, this fell far short of what was needed. Furthermore, selling the underlying collateral drives asset prices down, which then reinforces the cycle: lower prices, less collateral, more concerns about solvency, and ever increasing haircuts.

In addition to repo, other short-term debt also experienced runs. There were runs, in particular, on asset-backed commercial paper programs and structured investment vehicles. Papers that document the runs on asset-backed commercial paper programs during the crisis include Covitz, Liang, and Suarez (2009) and Carey, Correa, and Kotter (2009). Aside from asset-backed commercial paper, the commercial paper of financial firms, the predominant issuers of corporate short-term commercial paper also saw withdrawals when investors refused to reinvest as the paper came due; see Kacperczyk and Schnabl (2010). ${ }^{4}$ Also, important was the run on money market funds following the failure of Lehman Brothers, as documented by The Investment Company Institute (2009). In summary, all short-term debt markets were vulnerable during the crisis. In this paper, we focus on the repo market because of its large size (discussed

\footnotetext{
${ }^{4}$ The crises and other problems in the corporate commercial paper market were reminiscent of early crises in these markets; see Calomiris (1994) and Calomiris, Himmelberg and Wachtel (1995).
} 
below). Also, repo is secured by collateral that can be reused ("rehypothecated"), which means that a depositor of cash in the bank takes physical possession of bond collateral and then can reuse that the collateral. So, the collateral has a "money multiplier." When haircuts rise, the money multiplier works in reverse, causing a massive deleveraging process. This does not happen for unsecured short-term debt.

This paper and those mentioned above, are part of a rapidly growing literature that tries to empirically document what happened during the crisis. Aside from runs the financial crisis is complicated in many other dimensions as well. There are studies of the breakdown of various arbitrage relationships, perhaps due to counterparty risk and attendant funding problems, e.g., Coffey, Hrung, and Sarkar (2009), Gorton (2010), Baba and Packer (2009), Stanton and Wallace (2009), Fontana (2009), and Fender and Scheicher (2009). Other research looks at counterparty risk and liquidity, e.g., Arora, Gandhi, and Longstaff (2009), Schwarz (2009), and Singh and Aitken (2009). There are also papers that document the international dimensions of the crisis, and compare the crisis to previous crises, e.g., Eichengreen, Mody, Nedeljkovic, and Sarno (2009) and Reinhart and Rogoff (2008). Ivashina and Scharfstein (2008) look at bank lending during the crisis. The real effects of the crisis are also important to document, e.g., Almeida, Campello, and Laranjeira (2009) or Campello, Giabona, Graham, and Harvey (2009). Many other papers look at subprime mortgages, rating agencies, auction rate securities, short selling prohibitions, and so on, so the above list is very far from being complete. ${ }^{5}$

The remainder of the paper is organized as follows. In Section I, we provide institutional background for our analysis, with a discussion of the growth of securitized banking, using subprime mortgages as the case study. We use this case study to provide more detail for Step 4 in Figure 2, and to explain the mechanics of securitization and the repo market.

In Section II, we introduce and explain the two main state variables used in the paper: the ABX index - which proxies for fundamentals in the subprime mortgage market - and the LIBOIS, which is the spread between the LIBOR rate (for unsecured interbank borrowing) and the rate on an overnight interest swap, OIS (a proxy for the risk-free rate). As we will discuss below, in our analysis the LIB-OIS spread acts primarily as a proxy for counterparty risk in the banking system. We then plot these state variables for 2007 and 2008 and review the timeline

\footnotetext{
5 There is also a growing theory literature. Some examples are Acharya, Gale, and Yorulmazer (2009), Brunnermeier and Pedersen (2009), Geanakoplos (2010), Dang, Gorton and Holmström (2010a,b), He and Xiong (2009), Pagano and Volpin (2009), Shleifer and Vishny (2009), and Martin, Skeie, and von Thadden (2010).
} 
for the crisis. The $\mathrm{ABX}$ data show that the deterioration of the subprime market began in early 2007. As is now well known, this deterioration had a direct impact on banks, which had many of these securitized assets and pre-securitized mortgages on their balance sheets. This real deterioration in bank balance sheets became apparent in the interbank markets in mid-2007, as evidenced by an upward spike in the LIB-OIS in August. This state variable remained in a historically high but narrow range until September 2008, when the events at Fannie Mae, Freddie Mac, Lehman, and AIG led to a rapid deterioration in interbank markets and increase in the LIBOIS spread that persisted until the end of 2008 .

We posit that the increased risk at banks had several interrelated effects, all of which centered on the securitized assets used as collateral in the repo market. We provide evidence for these effects, using a data set with information on securitized bonds, credit-default swaps, and other assets used in repo transactions. These data were created by large financial institutions and are used for trading and portfolio valuation by a wide range of market participants. Section III provides summary statistics on these data and illustrates how some of these assets co-moved with the ABX and the LIB-OIS.

Section IV gives the main empirical results of the paper. Without a structural model of repo markets, we are only able to talk about co-movement of spreads on various assets, and thus we use the language of "correlation" rather than "causation" in our empirical analysis. Section IV.A explains our methodology and presents results for a few representative asset classes. Section IV.B uses the full set of asset classes to demonstrate that it was the interbank markets (LIB-OIS), and not the subprime housing market $(\mathrm{ABX})$, that was correlated with increases in the spreads on non-subprime securitized assets and related derivatives. These increased spreads are equivalent to a price decrease, which represents a fall in the value of collateral used in repo transactions. Then, as lenders began to fear for the stability of the banks and the possibility that they might need to seize and sell collateral, the borrowers were forced to raise repo rates and haircuts. Both of these increases occurred in the crisis. In Sections IV.C and IV.D, we find that these increases were correlated with changes in the LIB-OIS (for repo rates) and changes in the (expected future) volatility of the underlying collateral (for repo haircuts), consistent with the model of Dang, Gorton, and Holmström (2010). It is the rise in haircuts that constitutes the run on repo. An increase in a haircut is tantamount to a withdrawal from the bank, forcing deleveraging on a 
large scale. Section IV.E. uses data from Schwarz (2009) to confirm that the LIB-OIS relationships found for credit spreads and repo rates is primarily driven by counterparty risk.

Section V reviews our arguments and concludes the paper. Appendix A defines some of the paper's terminology that may be unfamiliar for some readers, and also includes descriptions for each of the asset classes of securitized bonds that are used in our empirical analysis. Appendix B gives more detail on the data construction.

\section{Institutional Background}

This section discusses the main institutional features that intersected in the crisis: the subprime mortgage market (Section I.A), securitization (Section I.B), and repo finance (Section I.C).

\section{A. The Subprime Mortgage Market}

The opportunity for home ownership for all Americans has been a long-standing national goal. This goal was behind the origins of modern housing finance during the Great Depression with the New Deal's National Housing Act of 1934 (see, e.g., Fishback, Horrace and Kantor (2001)). For example, as President Bush put it in 2004: "Not enough minorities own their own homes. ... One thing I've done is I've called on private sector mortgage banks and banks to be more aggressive about lending to first-time home buyers." 6 The private sector responded.

The subprime mortgage market is a financial innovation, aimed at providing housing finance to (disproportionately poor and minority) people with some combination of spotty credit histories, a lack of income documentation, or no money for a down payment. Historically, this group was perceived by banks as too risky to qualify for the usual mortgage products, for example, a 30-year fixed rate mortgage. As explained by Gorton (2010), the innovation was to structure the mortgage to effectively make the maturity two or three years. This was accomplished with a fixed initial-period interest rate, but then at the "reset date" having the rate rise significantly, essentially requiring the borrower to refinance the mortgage. With rising home prices, borrowers would build equity in their homes and would be able to refinance.

\footnotetext{
${ }^{6}$ See http://www.whitehouse.gov/news/releases/2004/03/20040326-15.html .
} 
The innovation was a success, if measured in terms of originations. In the years 2001-2006, a total of about $\$ 2.5$ trillion of subprime mortgages were originated. ${ }^{7}$ Almost half of this total came in 2005 and 2006, a large portion of which was likely refinancings of previous mortgages.

\section{B. Securitization}

An important part of the subprime mortgage innovation was how the mortgages were financed. In 2005 and 2006, about 80 percent of the subprime mortgages were financed via securitization, that is, the mortgages were sold in residential mortgage-backed securities (RMBS), which involves pooling thousands of mortgages together, selling the pool to a special purpose vehicle (SPV) which finances their purchase by issuing investment-grade securities (i.e., bonds with ratings in the categories of AAA, AA, A, BBB) with different seniority (called "tranches") in the capital markets. Securitization does not involve public issuance of equity in the SPV. SPVs are bankruptcy remote in the sense that the originator of the underlying loans cannot claw back those assets if the originator goes bankrupt. Also, the SPV is designed so that it cannot go bankrupt. ${ }^{8}$

RMBS are the largest component of the broader market for asset-backed securities (ABS), which includes similar structures for student loans, credit-card receivables, equipment loans, and many others. Figure 5 shows the annual issuance of debt in the important fixed income markets in the U.S. The figure shows that: (1) the mortgage-related market is by far the largest fixedincome market in the U.S., by issuance; but further, (2), that restricting attention to nonmortgage instruments, the asset-backed securitization market is very large, exceeding the issuance of all corporate debt in the U.S. in 2004, 2005, and 2006. Overall, the figure shows that securitization is a very large, significant, part of U.S. capital markets.

Securitization spawned a large number of new financial instruments and new usages for old instruments. Among these are asset-backed securities (ABS), credit default swaps (CDS), collateralized debt obligations (CDOs), and collateralized loan obligations (CLOs). ${ }^{9}$ Credit default swaps are derivative contracts under which one party insures another party against a loss due to default with reference to a specific corporate entity, asset-backed security, or index. For

\footnotetext{
${ }^{7}$ See Inside Mortgage Finance, The 2007 Mortgage Market Statistical Annual, Key Data (2006), Joint Economic Committee (October 2007).

${ }^{8}$ On the process of securitization generally, see Gorton and Souleles (2006).

${ }^{9}$ Other innovations, like structured investment vehicles, synthetic CDOs, and so on, are discussed in Gorton (2010). Gorton and Pennacchi (1995) discuss loan sales by banks.
} 
our purposes, the CDS spread, which is the fixed coupon paid by the party buying the protection, is an indication of the risk premium with regard to the specified corporate entity. CDOs are securitizations of corporate bonds or asset-backed or mortgage-backed securities. CLOs are securitizations of loans to corporations. CDOs are relevant here for two reasons. First, the underlying CDO portfolios contained tranches of subprime securitizations, making their value sensitive to subprime risk. And second, like asset-backed securities generally, they too depend on the repo market, at least to some extent.

Figure 6 shows how the pieces of the securitization process fit together. This figure is an expansion of Step 4 from the securitized-banking diagram shown in Figure 2, and also includes Step 1 from Figure 2, while omitting Steps 2 and 3. The starting point is a bank with a set of loans in its "inventory". The bank does not have the resources to keep all of these loans on its balance sheet - in securitized-banking the profit comes from the intermediation, not from holding the loans. In Step 4, these loans are transferred to the SPV and placed in one big pool. This pool is the assets of the SPV, which builds a capital structure on those assets using different layers, called tranches. The idea here is that the first losses on the pool will be allocated to the equity layer at the bottom, with additional losses moving up the capital structure, by seniority, until they reach the AAA tranche at the top. These layers and rating are represented by the assetbacked securities (ABS) issued by the SPV. Since the assets backing these securities are mortgages, the ABS goes by the specialized name of residential-mortgage-backed securities (RMBS) in this case.

The ABS may be sold directly to investors (Step 5), or may instead be securitized in a CDO (Step 6). A CDO will have a tranche structure similar to an ABS. The tranches of the CDO may be sold directly to investors (Step 7), or resecuritized into further levels of CDOs (not shown in figure). In some cases, the ABS or CDO tranches may return to the balance sheets of the banks, where they may be used as collateral in the repo transaction of Step 1.

With each level of securitization, the SPV often combines many lower-rated (BBB, BBB-) tranches into a new vehicle that has mostly AAA and AA rated tranches, a process that relies on well-behaved default models. This slicing and recombining is driven by a strong demand for highly rated securities for use as investments and collateral: essentially, there is not enough AAA debt in the world to satisfy demand, so the banking system set out to manufacture the supply. As emphasized by Gorton (2010), it can be very difficult to pierce the veil of a CDO and learn 
exactly what lies behind each tranche. This opacity was a fundamental part of pre-crisis securitization, and was not limited to subprime-based assets. ${ }^{10}$

\section{The Repo Market}

A repurchase agreement (or "repo") is a financial contract used by market participants as a financing method to meet short-term liquidity needs. ${ }^{11} \mathrm{~A}$ repurchase agreement is a two-part transaction. The first part is the transfer of specified securities by one party, the "bank" or "borrower," to another party, the "depositor" or "lender," in exchange for cash: the depositor holds the bond, and the bank holds the cash. ${ }^{12}$ The second part of the transaction consists of a contemporaneous agreement by the bank to repurchase the securities at the original price, plus an agreed upon additional amount on a specified future date. It is important to note that repurchase agreements, like derivatives, do not end up in bankruptcy court if one party defaults. The nondefaulting party has the option to simply walk away from the transaction, keeping either the cash or the bonds. ${ }^{13}$

In the last thirty years, the demand for repo has grown enormously. The main reason is the rapid growth of money under management by institutional investors, pension funds, mutual funds. In addition, demand for repo has also come from states, municipalities, and nonfinancial firms. These entities hold cash for various reasons, but would like to have a safe investment, which earns interest, while retaining flexibility to use the cash, in short, a demand deposit-like product. Insured checking accounts were imperfect substitutes for repo finance because of limitations on deposit insurance, differences in regulatory regimes applied to depository and repo finance (e.g., capital requirements), and other factors. In the last three decades these entities

\footnotetext{
${ }^{10}$ As explained by Gorton and Pennacchi (1990) and Dang, Gorton, and Holmström (2010), such opacity makes these instruments liquid by preventing adverse selection.

${ }^{11}$ For background on the repo market, see Corrigan and de Terá (2007) and Bank for International Settlements (1999).

${ }^{12}$ The collateral received by the depositor in repo may be rehypothecated, that is, the depositor can use it in another, unrelated, transaction. This creates a multiplier process for collateral, like the more familiar money multiplier. Since there are no official data on repo, the size of this money multiplier is not known. Singh and Aitken (2010) try to estimate the extent of rehypothecation. Fegatelli (2010) looks at this issue using data from Clearstream, a Luxembourg based clearinghouse. Also, see Adrian and Shin (2008) who link the use of repo to monetary policy.

13 Sale and repurchase agreements, like derivatives, have a special status under the U.S. Bankruptcy Code. Repurchase agreements are exempted from the automatic stay, so that a party to a repurchase agreement can unilaterally enforce the termination provisions of the agreement as a result of a bankruptcy filing by the other party. Without this protection, a party to a repo contract would be a debtor in the bankruptcy proceedings. See, e.g., Johnson (1997) and Schroeder (1999). The safe harbor provision for repo transactions was recently upheld in court in a case involving American Home Mortgage Investment Corp. suing Lehman Brothers. See Schweitzer, Grosshandler, and Gao (2008). In Gorton and Metrick (2010), we argue that this bankruptcy safe-harbor was a primary driver of the growth of repo.
} 
have grown in size and become an important feature of the financial landscape. For example, according to the BIS (2007); "In 2003, total world assets of commercial banks amounted to USD 49 trillion, compared to USD 47 trillion of assets under management by institutional investors" (p. 1 footnote 1$)$.

Mutual funds, including in particular MMMFS, are important users of repo. MMMFs held $\$ 552$ billion in repurchase agreements in December 2008 (Report of the Money Market Working Group (2009)). These data are for MMMFs only; there are no data covering all other types of mutual funds. The importance of repo for mutual funds motivated eight of the larger fund companies to send a letter (see Letter June 11, 2010) to Barney Frank and Chris Dodd expressing concern part of the proposed financial reform legislation "which would result in significant unintended consequences for the capital markets. The provision would likely curtail the desire of market participants to invest in repurchase agreements ("repos") ..."

Corporate treasurers and state and local governments started to expand their use of repo in the 1960s and 1970s, even though repurchase agreements were not standardized until the late 1980s. Stigum and Crescenzi (2007) note that corporate treasurers started to use repo in the 1960s: "By the mid-1970's, most corporations, including many that a few years earlier did not know what repo was, had amended their bylaws to permit them to invest in repo" (p. 536). Corporations use repo to manage their cash. The Association for Financial Professionals (AFP) conducts an annual liquidity survey; the 2006 survey reports that 60 percent of their 342 respondents allow repurchase agreements for their cash management. Of those, 57 percent are allowed to use 50 percent or more of their cash in repo, although in practice the allocation to repo is much less (AFP (2006)).

These nonfinancial firms also have been increasing the amounts of cash that their treasury departments hold (in part, perhaps, because of the increasing availability of repo). Bates, Kahle and Stulz (2008) point out a secular trend that "the average cash-to-assets ratio for U.S. industrial firms more than doubles between 1980 and 2006." This ratio more than doubled from 10.5 percent in 1980 to 23.2 percent in 2006. In particular, the average firm can pay back all its debt obligations with its cash holdings. Foley, Hartzell, Titman and Twite (2006) also study this rise in cash holding by U.S. firms: "At the end of fiscal 2004, cash represented 10.5\% of the aggregate assets of all Compustat firms. While this is a large percentage, for many firms, the dollar value of cash holdings was also large. For example, at the end of 2004 cash holdings of 
Microsoft, General Motors, Ford, General Electric, Exxon Mobil, and Pfizer were respectively \$60.6 billion, \$36.0 billion, \$33.4 billion, \$23.2 billion, \$23.1 billion, and \$19.9 billion” (p. 1). Also, see Pinkowitz, Stulz and Williamson (2006). ${ }^{14}$

With regard to state and local governments, the Government Finance Officers Association (GFOA) published their first edition of Considerations of Governments in Developing a Master Repurchase Agreement in September 1986. The GFOA (2001) noted that: "Repurchase agreements became popular in the state and local government sector in the early 1970s, when interest rates rose to double-digit levels for the first time in this century. During that era, bank time deposits were restricted to minimum maturities of 30 days, making repos an attractive short-term investment alternative for public cash managers holding short-term, temporary funds" (p. 4).

The above evidence is suggestive, but the unfortunate reality is that there are no official data on repo other than what the Federal Reserve collects with regard data to the repo amounts done by the 19 primary-dealer banks. According to Fed data, primary dealers reported financing $\$ 4.5$ trillion in fixed income securities with repo as of March 4, 2008. ${ }^{15}$ But, we know that this covers only a fraction of the repo market in the U.S. ${ }^{16}$ The U.S. Bond Market Association (now known as the Securities Industry and Financial Markets Association) conducted a survey of repo and securities lending in 2005 , estimating that the total exceeded $\$ 5.21$ trillion.

One way to estimate the total size of the U.S. repo market is to base it on triparty repo data. Triparty repo peaked at \$2.8 trillion (see Task Force (2009)). Market participants anecdotally provided us with a range of views as to what fraction triparty repo is of the overall market. This leads to an estimate that the U.S. repo market is likely to be roughly the same size (or larger) than the total assets in the U.S. banking system of \$10 trillion. Using a different method, Singh and Aitken (2010) also find a repo market pre-crisis peak of about $\$ 10$ trillion. Finally, using still a third method, Bank for International Settlements economists Hördahl and King (2008) report that repo markets have doubled in size since 2002, "with gross amounts outstanding at year-end 2007 of roughly $\$ 10$ trillion in each of the U.S. and Euro markets, and another $\$ 1$ trillion in the UK repo market” (p. 37). Finally, the European repo market, widely

\footnotetext{
${ }^{14}$ The upward secular trend in firm cash holdings is pronounced across six of seven industrialized countries over the period 1991-2008, studied by Iskandar-Dattta and Jia (2010). Japan is the outlier, showing a decline.

${ }^{15}$ Flow of Funds data only covers the U.S. primary dealers and so is even lower than the Federal Reserve numbers.

${ }^{16}$ Federal Reserve Flow of Funds data only covers the U.S. primary dealers and so is even lower than the Federal Reserve numbers.
} 
viewed as being much smaller than the U.S. market was EUR 4.87 trillion in June 2009, having peaked at EUR 6.78 trillion in June 2007, according to the International Capital Markets Association (ICMA) European Repo Market Survey (2010). According to the figures published in the ICMA European Repo Market Survey of June 2009, the repo market globally grew at an average rate of $19 \%$ per annum between 2001 and 2007. While the available evidence is very suggestive that the repo market is very large, it is impossible to say exactly how large.

Another way to get a sense of the growth in the securitized-banking system is to compare the total assets in the traditional regulated banking system to the total assets in the dealer (investment) banks, since the latter rely more heavily on repo finance than the former. For this purpose, Federal Flow of Funds data are available, shown in Figure 7. The figure shows that the ratio of broker-dealer total assets to commercial banks' total assets has grown from less than 5 percent in 1990 to a peak near 25 percent in 2007.

Some evidence on the use of repo in dealer banks comes from King (2008) and Hördahl and King (2008); the latter paper states that "the (former) top U.S. investment banks funded roughly half of their assets using repo markets, with additional exposure due to off-balance sheet financing of their customers" (p. 39). Some details on dealer use of repo are shown in Table I and are consistent this quotation and with Lehman Brothers bankruptcy report (Report of Anton R. Valukas (2010)) that: "Lehman funded itself through the short-term repo markets and had to borrow tens or hundreds of billions of dollars in those markets each day from counterparties to be able to open for business. Confidence was critical. The moment that repo counterparties were to lose confidence in Lehman and decline to roll over its daily funding, Lehman would be unable to fund itself and continue to operate." (p. 43)

Notably, commercial banks did not rely heavily on repo. The amount of securities sold under repo as a percentage of total assets from April 1, 2008 to February 29, 2009, was 63 basis points (mean) and the median was 2.7 percent (Afonso, Kovner, and Schoar (2010)). The crisis was centered on the dealer banks. In fact, commercial banks' balance sheets grew during the crisis (He, Khang and Krishnamurthy (2010)).

For every "repo," the other side of the transaction is a "reverse repo." This raises the issue of double counting of both repo and reverse repo. The issue concerns whether the relevant number is gross repo or net repo for financial firms. For example, a dealer bank that lent money via repo to a hedge fund (which provides the dealer bank with a bond as collateral) and then borrowed 
against that bond from another dealer bank would have a net of zero (ignoring the haircuts). But, in a run the depositors want their cash bank and the dealer bank cannot instantaneously get the cash back from the hedge fund. (This would be possible in a clearinghouse arrangement.) So, it would seem that gross repo borrowing is the relevant number. It is not known how much of the demand for repo comes from outside the banking system, i.e., are most of the depositor/end-users nonbanks? The extent of this issue is unclear as there are no data on the extent of involvement in repo from nonfinancial firms and only financial firms have been counted, estimated, or surveyed. As discussed above, at least anecdotally, many non-financial firms' treasury departments (e.g., Westinghouse, IBM, Microsoft) invest in repo as do institutional investors.

\section{State Variables: The ABX Indices and the LIB-OIS Spread}

This section introduces the key state variables of the paper. Section II.A discusses the ABX indices, which are proxies for fundamentals of the subprime market. Section II.B discusses the LIB-OIS spread, which is a proxy for fears about bank solvency. In Section II.C, we plot these two state variables against the timeline of the crisis.

\section{A. Subprime Fundamentals and the ABX Indices}

With respect to the housing market, the fundamentals essentially are housing prices and changes in housing prices. Subprime mortgages are very sensitive to housing prices, as shown by Gorton (2010). How was information about the fundamentals in the subprime mortgage market revealed to market participants? There are no secondary markets for the securities related to subprime (mortgage-backed securities, collateralized debt obligations). But, in the beginning of 2006 , the growth in the subprime securitization market led to the creation of several subprimerelated indices. Specifically, dealer banks launched the ABX.HE (ABX) index in January 2006. The $\mathrm{ABX}$ Index is a credit derivative that references 20 equally-weighted subprime RMBS tranches. There are also sub-indices linked to a basket of subprime bonds with specific ratings: AAA, AA, A, BBB and BBB-. Each sub-index references the 20 subprime RMBS bonds with the rating level of the subindex. Every six months the indices are reconstituted based on a preidentified set of rules, and a new vintage of the index and sub-indices are issued. ${ }^{17}$

\footnotetext{
${ }^{17}$ The index is overseen by Markit Partners. The dealers provide Markit Partners with daily and monthly marks. See http://www.markit.com/information/products/abx.html.
} 
Gorton (2009) argues that the introduction of the ABX indices is important because it opened a (relatively) liquid, publicly observable market that priced subprime risk. The other subprimerelated instruments, RMBSs and CDOs, did not trade in publicly observable markets. In fact, securitized products generally have no secondary trading that is publicly visible. Thus, for our purposes the $\mathrm{ABX}$ indices are important because of the information revelation about the value of subprime mortgages, which in turn depends on house prices. Keep in mind that house price indices, like the S\&P Case-Shiller Indices, are calculated with a two-month lag. ${ }^{18}$ Furthermore, house price indices are not directly relevant because of the complicated structure of subprime securitizations.

In this paper, we will focus on the BBB ABX tranche of the first vintage of the ABX in 2006, which is representative of the riskier levels of subprime securitization. We refer to this tranche of the 2006-1 issue simply as "ABX". In the next section, we show how the ABX evolved during the crisis, and compare this evolution with deterioration in the interbank markets.

\section{B. The Interbank Market and the LIB-OIS Spread}

Our proxy for the state of the interbank market and, in particular, the repo market, is the spread between 3-month LIBOR and the overnight index swap (OIS) rate, which we call the LIB-OIS spread. LIBOR is the rate paid on unsecured interbank loans, cash loans where the borrower receives an agreed amount of money either at call or for a given period of time, at an agreed interest rate. These loans are not traded. Basically, a cash-rich bank "deposits" money with a cash-poor bank for a period of time. The rate on such a deposit is LIBOR, which is the interest rate at which banks are willing to lend cash to other financial institutions "in size." The British Bankers' Association's (BBA) London interbank offer rate (LIBOR) fixings are calculated by taking the average of a survey financial institutions operating in the London interbank market. ${ }^{19}$ The BBA publishes daily fixings for LIBOR deposits of maturities up to a year.

From the 3-month LIBOR rate we will subtract a measure of interest rate expectations over the same term. This rate is the overnight index swap (OIS) rate. The overnight index swap is a

\footnotetext{
${ }^{18}$ See

http://www2.standardandpoors.com/portal/site/sp/en/us/page.topic/indices_csmahp/0,0,0,0,0,0,0,0,0,1,1,0,0,0,0,0.ht $\underline{\mathrm{ml}}$.

$\frac{19}{19}$ The BBA eliminates the highest and lowest quartiles of the distribution and average the remaining quotes. See Gyntelberg and Wooldridge (2008).
} 
fixed-to-floating interest rate swap that ties the floating leg of the contract to a daily overnight reference rate (here, the fed-funds rate). ${ }^{20}$ The floating rate of the swap is equal to the geometric average of the overnight index over every day of the payment period. When an OIS matures, the counterparties exchange the difference between the fixed rate and the average effective fed-funds rate over the time period covered by the swap, settling the trade on a net basis. The fixed quote on an OIS should represent the expected average of the overnight target rate over the term of the agreement. As with swaps generally, there is no exchange of principal and only the net difference in interest rates (times the notional amount) is paid at maturity, so OIS contracts have little credit risk exposure. ${ }^{21}$

If there is no credit risk and no transactions costs, then the interest rate on an interbank loan should equal the overnight index swap (the expected fed funds cost of the loan). To see this consider an example: Bank 1 loans Bank $2 \$ 10$ million for three months. Bank 1 funds the loan by borrowing $\$ 10$ million each day in the overnight fed-funds market. Further, Bank 1 hedges the interest-rate risk by entering into an overnight index swap under which Bank 1 agrees to pay a counterparty the difference between the contracted fixed rate and the overnight fed-funds rate over the next three months. In the past arbitrage has kept this difference below $10 \mathrm{bps}$.

If the spread between LIBOR and the OIS widens, there is an apparent arbitrage opportunity. But, at some times, banks are not taking advantage of it. Why? The answer is that there is counterparty risk: that is, Bank 1 worries that Bank 2 will default and so there is a premium between the expected interest rates over the period, the OIS rate, and the rate on the loan, LIBOR. We refer to the spread between the 3-month LIBOR and the 3-month OIS as "LIBOIS."

Ideally, we would like to use the LIB-OIS as a pure measure of counterparty risk in the banking system. Schwarz (2009) shows that this interpretation is too narrow, and that the LIBOIS reflects both counterparty risk and market-liquidity risk. In Section IV.E, we use Schwarz' data to divide the LIB-OIS into both counterparty and liquidity risk, and find that the counterparty component drives the vast majority of our results, and the liquidity component has

\footnotetext{
${ }^{20}$ There are equivalent swaps in other currencies, which reference other rates.

${ }^{21}$ In addition, credit risk in swaps is managed by requiring that collateral be posted to the party for which the swap becomes a liability.
} 
no explanatory power. Thus, in discussing the empirical results below, we refer to LIB-OIS as a proxy for counterparty risk, with the evidence for this interpretation given in Section IV.E.

\section{A Timeline for the Crisis}

In Figure 8, we show the ABX and LIB-OIS spreads. For the ABX, we use the 2006-1 BBB tranche in all cases. The time period is from January 1, 2007 through December 25, 2008. During the full period, the ABX makes a steady rise, whereas the LIB-OIS shows two jumps, in August 2007 and September 2008. These months are not particularly special for the ABX. Furthermore, the LIB-OIS recovers some ground at the end of 2008, while the ABX spread continues to grow. It is difficult to explain why the LIB-OIS spikes occur exactly at these times, and we are not attempting an explanation here. Instead, these figures are intended only to illustrate that the spikes are not concurrent with major changes in the ABX.

The first six months of 2007 were ordinary for the vast majority of fixed-income assets. It is only when we look at subprime-specific markets that we begin to see the seeds of the crisis. The $\mathrm{ABX}$ begins the year at 153 basis points (bps), which is close to its historical average since the series began in January 2006, after a first year with almost no volatility. The first signs of trouble appear at the end of January, and by March 1 the spread was 552bps. The next sustained rise came in June, reaching $669 \mathrm{bps}$ by the end of that month. In contrast, the LIB-OIS hardly moved during the period, steady at around 8bps.

Of particular interest is the summer of 2007, where the LIB-OIS first signals danger in the interbank market. From its steady starting value of 8 bps, LIB-OIS grows to 13 bps on July 26, before exploding past its historical record to $40 \mathrm{bps}$ on August 9, and to new milestones in the weeks ahead before peaking at $96 \mathrm{bps}$ on September 10. This period also marked the initial shock for a wide swath of the securitization markets, particularly in high-grade tranches commonly used as collateral in the repo market. The $\mathrm{ABX}$ is also rising during this period, but its most significant move begins earlier, and visually appears to lead the LIB-OIS. From its starting value of $669 \mathrm{bps}$ at the end of June, the spread rises to $1738 \mathrm{bps}$ by the end of July, before any significant move in the LIB-OIS.

The ABX spread continued its steady rise in the first half of 2008, going from $3812 \mathrm{bps}$ to 6721 bps over the six-month period from January 1 to June 30. Once again, the LIB-OIS is behaving differently from the ABX, with trading in a band between 30 and 90 bps. The reduction 
in the LIB-OIS in January is followed by increases through February and March, coincident - or perhaps causal - of the trouble at Bear Stearns, which reached its climax with its announced sale to JP Morgan on March 16.

In the second half of 2008, the full force of the panic hit asset markets, financial institutions, and the real economy. The ABX spread continued its steady rise, with prices of pennies on the dollar and spreads near $9000 \mathrm{bps}$ by the end of the period. The LIB-OIS, after a period of stability in the summer, began to rise in early September, and then passed the 100 bps threshold for the first time on the September 15 bankruptcy filing of Lehman Brothers. The subsequent weeks heralded near collapse of the interbank market, with the LIB-OIS peaking at $364 \mathrm{bps}$ on October 10, before falling back to 128 bps by the end of 2008 .

With this background, we turn next to the broad set of assets included in our data sets.

\section{Data}

Our data comes from dealer banks. The dealer banks observe market prices and convert these prices into spreads. The conversion of prices into spreads involves models of default timing and recovery amounts, and we are not privy to these models. However, one indication of the quality of the data is that it was the source for marking-to-market the books of some major financial institutions. The data set comprises 392 series of spreads on structured products, credit derivative indices, and a smaller set of single-company credit derivatives. In each case, the banks capture the "on-the-run" bond or tranche, which would be the spreads of interest to market participants. Fixed-rate bond spreads are spreads to Treasuries and floating-rate spreads are to LIBOR. Appendix B contains a brief discussion of spread calculation.

Some examples of the asset classes covered include spreads on credit-card securitization tranches, auto-loan securitization tranches, and all other major securitization classes. For each asset class, e.g., securitized credit-card receivables, there are spreads for each maturity, each rating category, and often for both fixed- and floating-rate bonds. For example, for fixed-rate credit-card receivables there are spreads for AAA bonds for maturities from two years to ten years. Also included are spreads on CDO and CLO tranches. Some series date back as far as January 2001, and others begin as late as 2006. Spreads are based on transactions prices, and if there are no such prices, then the series ends. 
Table II provides summary statistics on various categories of asset classes. Panel A shows the spreads in basis points. Our state variable, LIB-OIS spreads, are shown first, followed by representative asset classes that were exposed to subprime: home-equity loans (HEL), mezzanine-collateralized-debt obligations (Mezzanine CDO), home-equity lines-of-credit (HELOC); also shown are the CDS spreads for Countrywide and Washington Mutual ("Wamu"), two of the largest subprime mortgage originators; finally, three of the monoline insurers' CDS spreads are shown. These firms were alleged to have been heavily exposed to subprime risks via credit guarantees made on subprime-related bonds.

Throughout Table II there are five periods shown: the whole period (January 2007-January 2009); the first half of 2007, the second half of 2007, all of 2007, and "all of 2008" (which also includes January 2009). In general, the first half of 2007 looks "normal" in the sense that it is prior to the panic. Looking at LIB-OIS, for example, the average is about 8 basis points for the first half of 2007, consistent with no arbitrage and no counterparty risk. Also, note that AAA HELOC bonds traded at just over 15 basis points in the first half of 2007. The mortgage originators and monolines were also trading in normal spread ranges.

Looking at Panel A, it is clear that the subprime-related structured products and companies get hit in the second half of 2007. HEL, Mezzanine CDOs and HELOCs reach their peaks in the second half of 2007. Note that in the cases of HEL BBB and HELOC AAA there are no data in 2008; these markets simply disappear. ${ }^{22}$ This is also true of Countrywide, perhaps the largest originator of subprime mortgages. But, for WAMU and the monoline insurers the peak is in 2008.

The standard deviations are also worth noting. For the subprime-related structured asset classes, the peak of their spreads occurs in the second half of 2007, but the standard deviations are mostly highest in 2008. Thinking of standard deviations as a rough guide to uncertainty, this temporal sequence of rising uncertainty will be important later when we look at the repo market in detail.

Panel B shows asset classes that are non-subprime-related structured products based on U.S. portfolios: automobile loans, credit-card receivables, student loans, commercial mortgagebacked securities, high-grade structured-finance CDOs (HG SF CDO), and mezzanine

\footnotetext{
${ }^{22}$ The dealer banks only use on-the-run prices to calculate spreads. If there are no on-the-run prices, no spreads are calculated.
} 
structured-finance CDOs (Mezzanine SF CDO). In each case, we show the AAA tranches. In the first half of 2007, the normal state of affairs is that AAA asset-backed securities traded below LIBOR, true of auto loans, credit card receivables, and student loans. For the six categories shown, there are increases in the spreads in the second half of 2007, but the large increases are in 2008.

Figure 9 is an illustration of the time-series patterns for a few of these non-subprime asset classes: automobile loans, credit-card receivables, and student loans. In each case, the spreads appear to move closely with the LIB-OIS. These co-movements represent an important aspect of the crisis: the apparent relationship of the interbank market (LIB-OIS) with spreads on securities far removed from subprime housing. In Section IV, we will perform formal tests of these relationships.

The crisis was global. Panel C shows non-U.S. non-subprime-related asset classes, including mortgage-backed securities with portfolios of Australian, U.K., and Dutch mortgages. Also shown are U.K. credit-card receivables, European consumer loans, and European automobile loans. These categories are all trading normally in the first half of 2007, and show increases in their spreads during the second half of 2007. But, the spreads significantly widen in 2008, as do the standard deviations of their spreads.

Panel D summarizes our second data set which is on the interbank repo market. ${ }^{23}$ Shown are different categories of collateral, in each row. The categories themselves show how far the repo market has evolved from simply being a market related to U.S. Treasuries. For each category the annualized repo rate spread to the OIS is shown. These spreads are for overnight repo. ${ }^{24}$ Also shown is the average haircut on the collateral during the time period. For example, looking at the first category, BBB+/A Corporates, the average repo rate spread to OIS in the first half of 2007 was 2 bps, and the haircut was zero. Repo spreads for AA-AAA corporate bond collateral were negative for the first half of 2007. Overall, the patterns in repo are similar to those for the nonsubprime-related asset classes, that is, the spreads rise in the second half of 2007, but become dramatically higher in 2008. The haircuts also become dramatically higher in 2008. The market disappeared for unpriced CLO/CDO, unpriced ABS/MBS/all subprime, and for AA-AAA CDOs.

\footnotetext{
${ }^{23}$ Repo rates and haircuts could be different for non-dealer bank counterparties, such as hedge funds. This is discussed further later in the main text.

${ }^{24}$ Though not analyzed in this paper, the full term structure of repo spreads out to one year, tells a similar story.
} 
The last row in Panel E gives summary data for the Repo-Rate Index and the Repo-Haircut Index - the latter index is plotted in Figure 4 and discussed in the Introduction of this paper. During the time that all asset classes have active repo markets in 2007 and early 2008, the RepoRate Index is the equal-weighted average for all the asset classes. ${ }^{25}$ As haircuts rise to $100 \%$ for any given asset class (= no trade) on date $t$, we drop that class from the index and compute the index change for period $t$ using only the classes that traded in both period $t-1$ and period $t$. The Repo-Haircut Index is always equal to the average haircut on all nine of the asset classes, with 100 percent rates included in this average if the asset class disappears.

\section{Empirical Tests}

\section{A. Methodology and Basic Tests}

We want to test whether the spreads on U.S. non-subprime-related asset classes (AAA tranches) move with our state variables for the subprime market (ABX) and for interbank counterparty risk (LIB-OIS). For each asset, we want to estimate

$$
S_{i, t}=a_{0}+a_{1} t+b_{1} \mathbf{A B} \mathbf{X}_{t}+b_{2} \mathbf{L I B}-\mathbf{O I S}_{t}+b_{3} \mathbf{X}_{t}+e_{i, t},
$$

where $t$ is time a weekly time index, $S_{i, t}$ is the spread on asset $i$ at time $t, \mathrm{a}_{0}$ is a constant, $\mathrm{a}_{1}$ is a time trend, $\mathbf{A B X} \mathbf{X}_{\mathbf{t}}$ is a vector of the last four observations of the $\mathrm{ABX}$ spread including the current period, LIB-OIS $_{\mathbf{t}}$ is a vector of the last four observations of the LIB-OIS spread including the current period, and $\mathbf{X}_{\mathbf{t}}$ is a vector of control variables. Since the $S_{i, t}$ spreads are more similar to unit-root prices than to i.i.d returns, and since these levels vary significantly over our time period, we take first differences of (1) and normalize all changes by their level in the previous period:

$$
\Delta S_{i, t}=a_{1}+b_{1} \Delta \mathbf{A B X} \mathbf{X}_{t}+b_{2} \Delta \mathbf{L I B}-\mathbf{O I S}_{t}+b_{3} \Delta \mathbf{X}_{t}+e_{i, t}
$$

where the $\Delta$ prefix indicates the percentage change of the variable or vector. (Throughout our analysis, all references to "changes" will be to "percentage changes".) While there is a small

\footnotetext{
${ }^{25}$ There are no data available on the amounts of each asset class used as collateral in repo.
} 
literature on corporate-bond spreads (see Collin-Dufresne, Goldstein, and Martin (2001), and the citations therein), there are no studies of spreads on securitized products. We follow CollinDufresne, Goldstein, and Martin (2001) in their choice of control variables: ${ }^{26}$

- The 10-year constant maturity treasury rate (10YTreasury),

- The square of 10YTreasury, (10YTreasured Squared)

- The weekly return of the SP500 Index (SP500_ret).

- The VIX index (VIX) is a measure of the volatility of the S\&P index, produced by and traded on the Chicago Board of Trade. the new version introduce in 2003, is based on the options prices of the broader S\&P 500 index. Its square approximates the conditional risk-neutral expectation of the annualized return variance over the next 30 calendar days and thus the corresponding variance swap rate. See Carr and $\mathrm{Wu}(2006)$.

- The slope of the yield curve, (YCSlope), defined as the difference between the 10-year and 2-year Treasury bond interest rates.

- The overnight swap spread (OIS).

Panel E of Table II gives summary data on these control variables. Notably, the 10-year Treasury rate and the OIS rate both decline significantly in 2008, reflecting the Fed's actions. The return on the S\&P is negative in 2008. And, notably, the VIX index in 2008 is about double its level in 2007. In each case, the control variables are first-differenced for estimation of Equation (2).

Some preliminary regression results are given in Table III. Panel A shows the results for the six asset classes of U.S. non-subprime-related assets (AAA tranches) shown in Table II, Panel B. At the bottom of the table are F-tests corresponding to the hypothesis that the coefficients on the ABX variables are jointly zero and that the coefficients on the LIB-OIS variables are jointly zero. For the four securitization categories - credit cards, auto loans, student loans, and commercial mortgage-backed securities - the LIB-OIS variables are jointly significant. F-tests also show that the ABX coefficients are not jointly significant in any of the regressions. For the

\footnotetext{
${ }^{26}$ Since most of our series are not related to specific companies, we omit the company-specific control variables used by Collin-Dufresne, Goldstein, and Martin (2001).
} 
two categories of $\mathrm{CDO}$, high grade $(\mathrm{HG})$ and mezzanine, neither the LIB-OIS nor the ABX are significant.

Panel B of Table III addresses the global aspects of the crisis. Panel B covers non-U.S. nonsubprime related asset classes, the same ones displayed in Panel C of Table II. All of these asset classes are significantly affected by LIB-OIS, but not by the ABX.

\section{B. Credit Spreads for All Categories and Tranches}

Table III focuses on a subset of the available asset categories, a subset that we think is of particular interest, but nevertheless a subset. Table IV summarizes the F-tests for the joint significance of the changes in LIB-OIS, for the full set of asset categories, broken down into the following categories: subprime-related, U.S.; non-subprime-related; non-U.S. non-subprimerelated; financial firms (CDS spreads); and industrial firms (CDS spreads). The table has three panels, corresponding to the whole period from January 4, 2007 to January 29, 2009, and subperiods. We also performed similar F-tests for the ABX and lags on all asset categories. These results are not tabulated, because there is nothing of interest to show: overall, changes in the $\mathrm{ABX}$ are no better than noise at predicting changes in spreads.

Some highlights from Table IV are as follows. Subprime-related asset categories and the broad-array of financial firms are not typically correlated to the LIB-OIS. But, for the overall period, Panel A, 66 percent of the U.S. non-subprime asset classes are significantly positively correlated at the 10 percent confidence level. Similarly, 76 percent of the non-U.S. non-subprime categories are positively correlated at the 10 percent level or lower. Note that most of this occurs in 2007 for the non-U.S. structured products, but for the U.S. non-subprime structured products it is split across 2007 and 2008. Also, note that for 2008, Panel C shows that 75 percent of the industrials are significantly, positively correlated to changes in LIB-OIS, indicating the real affects hitting the economy. In 2007, Panel B, there are no such real effects.

Table V presents the F-test results divided by rating category. Assets in all rating categories were eligible for repo, but AAA collateral was likely to be the most widely used. The table is suggestive in this regard, but not definitive. Looking at the whole period, Panel A, $62 \%$ of the AAA products were positively and significantly correlated with changes in LIB-OIS. This is about equally divided between the two sub-periods. For AA, A and BBB rated bonds, the 
percentages that are significantly positive for the whole period are 28, 55 and 53 percent, respectively. For $\mathrm{A}$ and $\mathrm{BBB}$ this is about equally divided between the two subperiods.

\section{Repo Spreads}

In a world with known and certain values for collateral and no transactions costs for selling collateral, repo rates should be equal to the risk-free rate, and spreads would be zero: a lender/depositor would have no fear of default, since the collateral could be freely seized and sold. In reality, collateral pricing can be uncertain, and illiquidity and volatility in the secondary markets for this collateral can induce large transactions costs following a default. In this case, measures of bank-counterparty risk (LIB-OIS) may be relevant to lenders, and in the case of default they would be sensitive to uncertainty about collateral values. Lenders could then demand higher rates and/or higher haircuts. Higher rates would occur because the loans are no longer risk free; higher haircuts could occur to adjust for the uncertain value of the collateral, since each dollar of collateral may worth much less by the time it can be sold.

To test for the quantitative importance of these relationships, we first estimate a version of Equation (2) for repo spreads:

$$
\Delta R_{j, t}=a_{1}+b_{1} \Delta \mathbf{A B X} \mathbf{X}_{t}+b_{2} \Delta \mathbf{L I B}-\mathbf{O I S}_{t}+b_{3} \Delta \mathbf{X}_{t}+b_{4} \Delta \mathbf{V O L}_{j, t}+e_{i, t}
$$

where $R_{j, t}$ is the average spread of repo rates to the OIS for some class $\mathrm{j}$ of collateral (as in Table II, Panel D), VOL $\mathbf{~}_{\mathbf{j}, \mathbf{t}}$ is a vector of the last four "expected volatilities" (defined below) for that class of collateral, and all other variables are defined as in Equation (2).

$\mathrm{VOL}_{\mathrm{j}, \mathrm{t}}$ is a forward-looking measure, defined here as the average absolute (weekly) change in spreads over the next four weeks ${ }^{27}$ :

$$
V O L_{j, t}=\sum_{s=1}^{4}\left(\frac{\left|\Delta S_{j, t+s}\right|}{4}\right),
$$

where $S_{j, t}$ is the average spread to OIS for all assets in class $\mathrm{j}$ :

\footnotetext{
${ }^{27}$ All results are qualitatively similar if we use the eight weeks or twelve weeks instead of four weeks.
} 


$$
S_{j, t}=\bar{S}_{i, t}, i \in j
$$

$\Delta \mathrm{VOL}_{\mathrm{j}, \mathrm{t}}$ is defined as the difference between expected volatility today and realized volatility over the previous four weeks (not including the current week):

$$
\Delta V O L_{j, t}=V O L_{j, t}-V O L_{j, t-5} .
$$

Note that volatility uses absolute differences, and not percentage differences, because percentage differences are harder to interpret across multiple weeks. Also, since we use future information for our expected-volatility proxy, the resulting estimates could not be part of an implementable investment strategy. This restriction does not matter for our analysis, since we are not seeking to build investment portfolios from these results. In any case, we don't really have a choice here, since there is no way to extract volatility expectations from historical spread data alone.

We estimate (3) for all five classes of collateral that have data available to construct the VOL measure. ${ }^{28}$ The regression results for these five classes are shown in Table VI. The final rows show the results of the F-tests for the joint significance of LIB-OIS (Test 1), the ABX (Test 2) and VOL changes (Test 3), respectively. These tests show that the changes in repo spreads are significantly related to the change in LIB-OIS for all five categories, with almost all of the effect coming in the contemporaneous period. Changes in repo spreads are not significantly related to changes in the ABX or VOL or to any of the other control variables. Thus, just as we found for credit spreads in our earlier analysis, the state variable for bank-counterparty risk is the only significant correlate with repo spreads.

\section{Repo Haircuts}

It seems natural that banks would have to raise repo spreads to attract funds. But, higher rates do not by themselves cause a systemic event. For a "run on repo", we need to see that the depositors withdraw from the bank, that is, market participants demand higher repo haircuts. Figure 4 showed that this did occur. In this subsection we turn to examining repo haircuts.

\footnotetext{
${ }^{28}$ For the other four classes of collateral shown in Panel D of Table I, we do not have data for the spreads of the underlying assets.
} 
First, as regards the data, the size of repo haircuts depends on the identities of the counterparties and on the type of collateral. See Dang, Gorton, and Holmström (2010b) for a discussion of this point. Our data set is from a high-quality dealer bank transacting with other high-quality dealer banks. Other repo data that we have involves different types of counterparties, e.g., a dealer bank providing collateralized funds to a hedge fund, via reverse repo. The haircuts that a hedge fund faces when borrowing from a dealer bank are larger than what the dealer faces in the interbank market, for the same bond (on the same date). All the haircut data sets show the same pattern as displayed in Figure 4, but they do not all start at zero haircuts prior to the crisis. The data set we analyze here is the most extensive.

Haircuts are a puzzle. If "depositors" in the repo market, receiving collateral to protect their deposits, were concerned that the bank might fail, causing them to need to sell the collateral, then the risks of what price they would realize would enter their calculation. If the market for the collateral is volatile, then standard finance theory suggests that they should ask for a higher repo rate initially. Dang, Gorton, and Holmström (2010a,b) argue that debt, and repo in particular, are optimally designed securities which are used to intertemporally transport value. Their design is such as to minimize the variance of their value in the face of public shocks. A "haircut" is sometimes needed to protect against such volatility and provide an incentive for a counterparty to repurchase the security. Dang, Gorton, and Holmström (2010b) predict that haircuts are increasing in expected future volatility. We next explore the factors related to these increases using the same regression framework as we did for repo spreads:

$$
\Delta H_{j, t}=a_{1}+b_{1} \Delta \mathbf{A B X} \mathbf{X}_{t}+b_{2} \Delta \mathbf{L I B}-\mathbf{O I S}_{t}+b_{3} \Delta \mathbf{X}_{t}+b_{4} \Delta \mathbf{V O} \mathbf{L}_{j, t}+e_{i, t}
$$

where $H_{j, t}$ is the average haircut for all assets in class $\mathbf{j}$, and all other variables are defined as in (3). ${ }^{29}$ Since haircuts are already defined as a percentage of the total value of the underlying collateral, the change in haircuts on the left-hand-side of equation (7) is already given in percentages. Table VII summarizes the results. As we have found in earlier tests, the ABX and the control variables are not significant. In contrast to previous regressions, the change in the

\footnotetext{
${ }^{29}$ It may seem natural that repo spreads and repo haircuts should be jointly determined. Unfortunately, as discussed below, the theory is not sufficiently developed to provide much guidance here, especially with regard to identification.
} 
LIB-OIS is also not significant. The only variable with any explanatory power is the proxy for expected volatility, which is significant for three of the five classes of collateral.

The key finding here is that both repo spreads and repo haircuts rose during the crisis, with these increases correlated either to concerns about counterparty risk (for spreads), or to uncertainty about collateral values (for haircuts). While these results are somewhat different for spreads and haircuts, we suspect that this system is jointly determined, and that a disruption in the interbank market and increases in uncertainty about collateral are both necessary conditions for a run on repo. In an environment with no counterparty risk, there is no reason to expect haircuts to be affected by uncertainty about collateral; similarly, high counterparty risk by itself would be unlikely to affect repo spreads if all collateral had fixed values and liquid markets. It seems unlikely that nature will give us an example with rising VOL but no change in LIB-OIS. Instead, all of these things happened at the same time, and it is not possible to disentangle the exact causes.

\section{E. LIB-OIS: Counterparty Risk or Market-Liquidity Risk?}

Our results show a strong correlation between the LIB-OIS and both credit spreads and repo rates, and we have interpreted the LIB-OIS as a proxy for counterparty risk. However, Schwarz (2009) demonstrates that, during the early stages of the crisis, the LIB-OIS was driven at least as much by market-liquidity risk as by counterparty risk. We can use Schwarz' data and methods to decompose the LIB-OIS relationships for part of our sample period. For these tests, we use Schwarz' "credit-tiering" measure, which represents the average spread in overnight borrowing rates between "high-risk" and "low-risk" banks. ${ }^{30}$ As shown in Schwarz (2009), this measure can be thought of as a proxy for counterparty risk, and it explains some (but not most) of the variation in LIB-OIS from January 1, 2007 through April 30, 2008, the last date that her series is available.

In our first set of tests, we replace the $\Delta$ LIB-OIS variables in (2), (3) and (4) with analogous changes in the credit-tiering measure. The results - for the time period through April 30, 2008 - are almost as strong as for the LIB-OIS variable over the same time period. For 176 non-subprime related U.S. bond spreads, the credit-predicted component is significant 60 times

\footnotetext{
${ }^{30}$ We thank Krista Schwartz for sharing her credit-tiering measure with us. See Schwartz (2009) for details on the construction of this measure and its relationship to market liquidity and LIB-OIS.
} 
at the one-percent level and an additional 28 times at the five-percent level. These results suggest that Schwartz (2009) credit-tiering measure may be the ideal proxy for counterparty risk - even better than LIB-OIS, which is contaminated by other factors - if it were available for the entire sample period. For the haircut regressions in (4), the credit-tiering measure - like LIB-OIS - is insignificant in all cases. ${ }^{31}$

In our second set of tests, we employ a two-step procedure. We first regress LIB-OIS on the credit-tiering measure, and use the point estimate of the coefficient from this regression to decompose LIB-OIS into a "credit-predicted variable" and a residual, and into weekly changes for both of those components. The residual here would include market-liquidity and any other unexplained portions of LIB-OIS. We then replace $\Delta$ LIB-OIS with these two components predicted and residual - in (2), (3), and (4). We find that the credit-predicted component performs much better than the residual for predicting credit spreads and repo rates. For example, for the 176 non-subprime related U.S. bond spreads, the credit-predicted component is significant 35 times at the one-percent level and an additional 31 times at the five-percent level. In contrast, the residual is never significant for these bonds at the one-percent level, and only four times at the five-percent level - less than would be expected by chance. Thus, for the early part of the crisis, it seems that the counterparty-risk component of LIB-OIS is much more important for our results than is the market-liquidity component.

Overall, these results support the interpretation of LIB-OIS as a proxy for counterparty risk in our results.

\section{Conclusion}

How did problems in the subprime mortgages cause a systemic event? Our answer is that there was a run in the repo market. The location and size of subprime risks held by counterparties in the repo market were not known and led to fear that liquidity would dry up for collateral, in particular non-subprime related collateral. Public shocks causing expected future spread volatility led to increases in the repo haircuts, which is tantamount to massive withdrawals from the banking system.

The banking system has changed, with "securitized banking" playing an increasing role alongside traditional banking. One large area of securitized banking - the securitization of

\footnotetext{
${ }^{31}$ Detailed tables of all the results for this section are available from the authors.
} 
subprime home mortgages - began to weaken in early 2007 , and continued to decline throughout 2007 and 2008. But, the weakening of subprime per se was not the shock that caused systemic problems. The first systemic event occurs in August 2007, with a shock to the repo market that we demonstrate using the "LIB-OIS," the spread between the LIBOR and the OIS, as a proxy. The reason that this shock occurred in August 2007 - as opposed to any other month of 2007 - is perhaps unknowable. We hypothesize that the market slowly became aware of the risks associated with the subprime market, which then led to doubts about repo collateral and bank solvency. At some point - August 2007 in this telling - a critical mass of such fears led to the first run on repo, with lenders no longer willing to provide short-term finance at historical spreads and haircuts.

After August 2007, the securitized-banking model was under pressure, with small equity bases stretched by increasing haircuts on high-grade collateral. We see evidence of this pressure in the co-movement of spreads on a wide variety of AAA and AA credits. This pressure contributed to the forced rescue of Bear Stearns in March 2008 and the failure of Lehman Brothers In September 2008. The second systemic event and run on repo occurred with the failure of Lehman. In this second event, we see parallels to $19^{\text {th }}$ century banking crises, with a famine of liquidity leading to significant premia on even the safest of assets. 


\section{References}

Acharya, Viral, Douglas Gale, and Tanju Yorulmazer (2009), "Rollover Risk and Market Freezes," New York University, working paper.

Adrian, Tobias and Hyun Shin (2008), "Liquidity, Monetary policy, and Financial Cycles," Current Issues in Economics and Finance, Vol. 14, No. 1, Federal Reserve Bank of New York (January/February).

Afonso, Gara, Anna Kovner and Antoinette Schoar (2010), "Stressed, Not Frozen: The Federal Funds Market in the Financial Crisis," New York Federal Reserve Bank, Staff Report No. 437.

Almeida, Heitor, Murillo Campello, and Bruno Laranjeira (2009), "Corporate Debt Maturity and the Real Effects of the 2007 Credit Crisis," University of Illinois, working paper.

Arora, Navneet, Priyank Gandhi, and Francis Longstaff (2009), "Counterparty Credit Risk and the Credit Default Swap Market," UCLA, working paper.

Association for Financial Professionals (2006), “AFP Liquidity Survey” Report of Survey Results; http://www.afponline.org/pub/pdf/2006LiquiditySurvey 1.pdf.

Baba, Naohiko and Frank Packer (2009), "From Turmoil to Crisis: Dislocations in the FX Swap Market Before and After the Failure of Lehman Brothers," BIS Working Paper, No. 285.

Bank for International Settlements (1999), "Implications of Repo Markets for Central Banks," Report of a Working Group established by the Committee on the Global Financial System of the Central Banks of the Group of Ten Countries, March 9, 1999.

Bank for International Settlements (2007), "Institutional Investors, Global Savings and Asset Allocation," Report submitted by a Working Group established by the Committee on the Global Financial System (February).

Bates, Thomas, Kathleen Kahle, and René Stulz (2008), "Why do U.S. Firms Hold So Much More Cash Than They Used to?," Ohio State University, working paper.

Bond Market Association (2005), "Repo \& Securities Lending Survey of U.S. Markets Volume and Loss Experience," Research (January).

Bond Market Association (2006), "Comments on Securities Lending Facility;" see http://www.sifma.org/regulatory/comment_letters/comment_letter_archives/signed\%20fo $\underline{\mathrm{r} \% 20 \mathrm{cc} . \mathrm{pdf}}$ 
Brunnermeier, Markus and Lasse H. Pedersen (2009), "Market Liquidity and Funding Liquidity," Review of Financial Studies 22(6), 2201-2238.

Calomiris, Charles W. (1994), "Is the Discount Window Necessary? A Penn Central Perspective," Federal Reserve Bank of St. Louis Review 76 (May/June), pp. 31-56.

Calomiris, Charles W., Charles P. Himmelberg, and Paul Wachtel, "Commercial Paper and Corporate Finance: A Microeconomic Perspective," Carnegie-Rochester Conference Series on Public Policy, XLI (1995), 203-250.

Campello, Murillo, Erasmo Giabona, John Graham, and Campell Harvey (2009), "Liquidity Management and Corporate Investment during a Financial Crisis," Duke University, working paper.

Carey, Mark, Ricardo Correa, and Jason Kotter (2009), "Revenge of the Steamroller: ABCP as a Window on Risk Choices," Board of Governors of the Federal Reserve System, working paper.

Carr, Peter and Liuren Wu (2006), "A Tale of Two Indices," The Journal of Derivatives (Spring), 13-29.

Coffey, Niall, Warren Hrung, and Asani Sarkar (2009), "Capital Constraints, Counterparty Risk and Deviations from Covered Interest Rate Parity," New York Federal Reserve Bank, working paper.

Collin-Dufresne, Pierre, Robert Goldstein, and Spencer Martin (2001), "The Determinants of Credit Spread Changes," Journal of Finance Vol. 56, No. 6: 2177-2207.

Corrigan, Danny and Natasha de Terán (2007), Collateral: Securities Lending, Repo, OTC Derivatives and the Future of Finance (Global Custodian; London).

Covitz, Daniel, Nellie Liang, and Gustavo Suarez (2009), "The Evolution of a Financial Crisis: Runs in the Asset-Backed Commercial Paper Market," Board of Governors of the Federal Reserve System, Working Paper No. 2009-36.

Dang, Tri Vi, Gary Gorton, and Bengt Holmström (2010a), "Financial Crises and the Optimality of Debt for Liquidity Provision," working paper.

Dang, Tri Vi, Gary Gorton, and Bengt Holmström (2010b), Repo Haircuts: No Title Yet, forthcoming working paper. 
Eichengreen, Barry, Ashoka Mody, Milan Nedeljkovic, and Lucio Sarno (2009), "How the Subprime Crisis Went Global: Evidence from Bank Credit Default Swap Spreads," NBER Working Paper 14904.

Fabozzi, Frank and Steven Mann (2000), Floating-Rate Securities (Wiley).

Fegatelli, Paolo (2010), "The Role of Collateral Requirements in the Crisis: One Tool for Two Objectives?," Banque central du Luxembourg, working paper.

Fender, Ingo and Martin Scheicher (2009), "The Pricing of Subprime Mortgage Risk in Good Times and Bad: Evidence from the ABX.HE Indices,” BIS Working Papers, No. 279.

Fishback, Price, William Horrace, and Shawn Kantor (2001), "The Origins of Modern Housing Finance: The Impact of Federal Housing Programs during the Great Depression," University of Arizona, working paper.

Foley, C. Fritz, Jay Hartzell, Sheridan Titman, and Garry Twite (2006), "Why Do Firms Hold So Much Cash? A Tax-based Explanation,” NBER working paper no. 12649.

Fontana, Allessandro (2009), "The Persistent Negative CDS-bond Basis during the 2007/2008 Financial Crisis," University of Ca' Foscari Venice, working paper.

Geanakoplos, John (2010), “The Leverage Cycle,” NBER Macroeconomics Annual 2009, vol. 24, 165, ed. D.Acemoglu, K. Rogoff, and M. Woodford (Chicago: University of Chicago Press).

Gorton, Gary (2010), Slapped by the Invisible Hand: The Panic of 2007 (Oxford University Press).

Gorton, Gary (2009), "Information, Liquidity, and the (Ongoing) Panic of 2007," American Economic Review, Papers and Proceedings, vol. 99, no. 2, 567-572.

Gorton, Gary (1985), "Clearinghouses and the Origin of Central Banking in the U.S.," Journal of Economic History 45:2 (June): 277-83.

Gorton, Gary and Lixin Huang (2006), "Banking Panics and Endogenous Coalition Formation," Journal of Monetary Economics, Vol. 53 (7): 1613-1629.

Gorton, Gary and Andrew Metrick (2010), "Regulating the Shadow Banking System," forthcoming in the Brookings Papers on Economic Activity. 
Gorton, Gary and Don Mullineaux (1987), "The Joint Production of Confidence: Endogenous Regulation and Nineteenth Century Commercial Bank Clearinghouses," Journal of Money, Credit and Banking 19(4): 458-68.

Gorton, Gary and Nicholas Souleles (2006), "Special Purpose Vehicles and Securitization," chapter in The Risks of Financial Institutions, edited by Rene Stulz and Mark Carey (University of Chicago Press).

Gorton, Gary and George Pennacchi (1995), "Banks and Loan Sales: Marketing Non-Marketable Assets," Journal of Monetary Economics 35(3): 389-411.

Gorton, Gary and George Pennacchi (1990), "Financial Intermediaries and Liquidity Creation," Journal of Finance 45:1 (March): 49-72.

Government Finance Officers Association (2001), Considerations for Governments in Developing a Master Repurchase Agreement, third edition.

Gyntelberg, Jacob and Philip Wooldridge (2008), "Interbank Rate Fixings During the Recent Turmoil,” Bank for International Settlements Quarterly Review (March), 59-72.

He, Zhiguo and Wei Xiong (2009), "Dynamic Debt Runs," Princeton University, Princeton, Working paper.

He, Zhiguo, In Gu Khang, and Arvind Krishnamurthy (2010), "Balance Sheet Adjustments during the 2008 Crisis," Kellogg School, Northwestern University, working paper.

Hördahl, Peter and Michael King (2008), "Developments in Repo Markets During the Financial Turmoil," Bank for International Settlements Quarterly Review (December), 37-53.

International Capital Market Association (2010), European Repo Market Survey Number 18conducted December 2009.

Investment Company Institute (2009), "Report of the Money Market Working Group," (March 17, 2009).

Iskandar-Datta, Mai and Yonghong Jia (2010), "Why Do Firms Hold so Much Cash? The International Evidence," Wayne State University, working paper.

Ivashina, Victoria and David Scharfstein (2008), "Bank Lending during the Financial Crisis of 2008," Working Paper, Harvard Business School. 
Johnson, Christian (1997), "Derivatives and Rehypothecation Failure: It's 3:00 p.m., Do You Know Where Your Collateral Is?,” Arizona Law Review 30(949).

Kacperczyk, Marcin and Philipp Schnabl (2010), "When Safe Proved Risky: Commercial Paper during the Financial Crisis of 2007-2009," Journal of Economic Perspectives 24(1), 29-50.

King, Matt (2008), “Are the Brokers Broken?,” Citibank Global Markets Group.

Martin, Antoine, David Skeie, and Ernst-Ludwig von Thadden (2010), "Repo Runs," Federal Reserve Bank of New York, Staff Report No. 444.

Pagano, M. and Volpin, P. 2008. “Securitization, Transparency, and Liquidity,” Working Paper.

Pinkowitz, Lee, René Stulz, and Rohan Williamson (2006), "Does the Contribution of Corporate Cash Holdings and Dividends to Firm Value Depend on Governance? A Cross-country Analysis," Journal of Finance 61: 2725-2751.

Reinhart, Carmen and Kenneth Rogoff (2008), "Is the 2007 U.S. Subprime Financial Crisis So Different? An International Historical Comparison," American Economic Review 98, 339344.

Report of Anton R. Valukas, In Re Lehman Brothers Holdings Inc., et al. Debtors, Chapter 11 Case No. 08-13555, United States Bankruptcy Court, Southern District of New York, March 10, 2010.

Report of the Money Market Working Group (2009), submitted to the Board of Governors of the Investment Company Institute (March 17, 2009).

Schroeder, Jeanne (1996), "Repo Madness: The Characterization of Repurchase Agreements Under the Bankruptcy Code and the U.C.C.," Syracuse Law Review 46, 999-1050.

Schwarz, Krista (2009), "Mind the Gap: Disentangling Credit and Liquidity Risk Spreads," Wharton School, working paper.

Schweitzer, Lisa, Seth Grosshandler, and William Gao (2008), "Bankruptcy Court Rules that Repurchase Agreements Involving Mortgage Loans are Safe Harbored Under the Bankruptcy Code, But That Servicing Rights Are Not," Journal of Bankruptcy Law (May/June), 357360 .

Shleifer, Andrei and Robert Vishny (2009), “Unstable Banking”, NBER working paper 14943. 
Singh, Manmohan and James Aitken (2009), "Counterparty Risk, Impact on Collateral Flows, and Role for Central Counterparties," IMF Working Paper WP/09/173.

Stanton, Richard and Nancy Wallace (2009), "The Bear's Lair: Indexed Credit Default Swaps and the Subprime Mortgage Crisis," Berkeley, working paper.

Stigum, Marcia and Anthony Crescenzi (2007), Stigum's Money Market, 4E(McGraw Hill).

Task Force on Tri-Party Repo Infrastructure (2010), “Report,” May 17, 2010.

Task Force on Tri-Party Repo Infrastructure (2009), Payments Risk Committee, "Progress Report," December 22, 2009. 


\section{Appendix A: Glossary of Key Terms and Asset Classes}

This glossary provides definitions for all terms given in bold in the body of the paper and all asset classes listed in Table 1. For the latter group, we include the panel location of that variable in parenthesis following the definition (e.g: Table I - Panel A).

AA-AAA ABS RMBS/CMBS: Residential mortgage-backed security (RMBS) or commercial mortgage-backed security (CMBS) with ratings between AA and AAA, inclusive. (Table I - Panel D)

<AA ABS RMBS-CMBS: Residential mortgage-backed security (RMBS) or commercial mortgage-backed security (CMBS) with ratings between AA and AAA, inclusive. (Table I Panel D)

AA-AAA CDO: Collateralized debt obligations (CDO) with ratings between AA and AAA, inclusive. (Table I - Panel D)

AA-AAA CLO: Collateralized loan obligations (CDO) with ratings between AA and AAA, inclusive. (Table I - Panel D)

A-AAA ABS Auto/CC/SL: Asset-backed securities (ABS) comprised of auto loans, credit-card receivables, or student loans, with ratings between A and AAA, inclusive. (Table I Panel D)

ABX, ABX Index, ABX Index Spread: The ABX Index is a credit derivative that references 20 equally-weighted subprime RMBS tranches. There are also sub-indices linked to a basket of subprime bonds with specific ratings: AAA, AA, A BBB and BBB-. Each sub-index references the 20 subprime RMBS bonds with the rating level of the subindex. Every six months the indices are reconstituted based on a pre-identified set of rules, and a new vintage of the index and subindices are issued. In this paper, we focus on the BBB ABX tranche of the first vintage of the $\mathrm{ABX}$ in 2006, which is representative of the riskier levels of subprime securitization. We refer to this tranche of the 2006-1 issue simply as "ABX".

Asset-Backed Securities (ABS): An asset-backed security is a bond which is backed by the cash flows from a pool of specified assets in a special purpose vehicle rather than the general credit of a corporation. The asset pools may be residential mortgages, in which case it is a residential mortgage-backed security (RMBS), commercial mortgages - a commercial 
mortgage-backed security (CMBS), automobile loans, credit card receivables, student loans, aircraft leases, royalty payments, and many other asset classes.

Australia RMBS AAA: AAA-rated RMBS backed by Australian mortgages. (Table I Panel C)

Auto AAA: AAA-rated ABS backed by auto loans. (Table 1 - Panel B)

BBB+/A Corporates: Corporate bonds rated between $\mathrm{BBB}+$ and $\mathrm{A}$, inclusive. (Table I Panel D)

Cards AAA: AAA-rated ABS backed by credit-card receivables. (Table I - Panel B)

CMBS AAA: AAA-rated Commercial-mortgage-backed securities. (Table I - Panel B)

Credit Default Swaps (CDS): A credit default swap is derivative contract in which one party agrees to pay the other a fixed periodic coupon for the specified life of the agreement. The other party makes no payments unless a specified credit event occurs. Credit events are typically defined to include a material default, bankruptcy or debt restructuring for a specified reference asset. If such a credit event occurs, the party makes a payment to the first party, and the swap then terminates. The size of the payment is usually linked to the decline in the reference asset's market value following the credit event.

Collateralized Debt Obligations (CDOs): A CDO is a special purpose vehicle, which buys a portfolio of fixed income assets, and finances the purchase of the portfolio via issuing different tranches of risk in the capital markets. These tranches are senior tranches, rated Aaa/AAA, mezzanine tranches, rated $\mathrm{Aa} / \mathrm{AA}$ to $\mathrm{Ba} / \mathrm{BB}$, and equity tranches (unrated). Of particular interest are ABS CDOs, which have underlying portfolios consisting of asset-backed securities (ABS), including residential mortgage-backed securities (RMBS) and commercial mortgage-backed securities (CMBS).

Collateralized Loan Obligations (CLOs): A CLO is a securitization of commercial bank loans.

Commercial Mortgage-backed Securities (CMBS): See asset-backed securities, above.

Dutch RMBS AAA: AAA-rated RMBS backed by Dutch mortgages. (Table I - Panel C)

European Auto AAA: AAA-rated ABS backed by European auto loans (Table I - Panel C)

European Consumer Receivables AAA: AAA-rated ABS backed by European consumer receivables (Table I - Panel C) 
Haircut: The collateral pledged by borrowers towards the repo has a haircut or "initial margin" applied, which means the collateral is valued at less than market value. This haircut reflects the perceived underlying risk of the collateral and protects the lender against a change in its value. Haircuts are different for different asset classes and ratings.

HEL BBB: BBB-rated ABS backed by Home-equity loans with BBB ratings (Table 1Panel A)

HELOC AAA: AAA-rated ABS backed by Home-equity lines-of-credit (Table I- Panel A)

HG SF CDO (High-grade structured-finance CDOs): High-grade structured-finance CDOs buy collateral consisting of the AAA and AA-rated tranches of securitized bonds. (Table 1 - Panel B)

Home-equity loans (HEL): A home equity loan is a line of credit under which a home owner can borrower using the home equity as collateral.

Home-equity lines-of-credit (HELOC): A HELOC differs from a home equity loan in that the borrower does not borrower the full amount of the loan at the outset, but can draw down the line of credit over a specified period of time with a maximum amount.

LIB-OIS: The spread between the LIBOR and the OIS.

LIBOR: The London Interbank Offered Rate (LIBOR) is a series of interest rates, of different maturities and currencies, at which banks offer to lend fund to each other. These rates are calculated by the British Bankers' Association as the averages of quotes contributed by a panel of banks and announced at 11:00 Am local time in England. This is called the rate "fixing." Quotes are ranked and the top and bottom quartiles are discarded. LIBOR is fixed for 15 different maturities, from overnight to one year, and in ten international currencies. Similar fixing arrangements exist in many markets around the world. See Gyntelberg and Wooldridge (2008).

Mezzanine SF CDO: A Mezzanine structure-finance CDO refers to a collateralized debt obligation where the underlying portfolio consists of tranches of different asset-backed securities that are rated between BBB and A, inclusive. (Table I - Panel B)

Monoline Insurers, Monoline Insurance Companies ("monolines"): Insurance companies that are restricted by regulation to one line of the business, the business of issuing financial guarantees on bonds, that is insurance against the loss due to default of specified bonds. The first such company was AMBAC Financial Group Inc., formed in 1971, followed by MBIA 
formed in 1983. In 1989 a law in New York limited the sale of financial insurance products by those companies solely to bond insurance, making them "monolines."

Mortgage Originators: Financial firms that underwrite and fund residential and possibly commercial, mortgages.

OIS: See Overnight Index Swap (Table I - Panel E).

Overnight Index Swap (OIS): An Overnight Indexed Swap (OIS) is a fixed/floating interest rate swap where the floating leg of the swap is tied to a published index of a daily overnight rate reference. The term ranges from one week to two years (sometimes more). At maturity, the two parties agree to exchange the difference between the interest accrued at the agreed fixed rate and interest accrued through geometric averaging of the floating index rate on the agreed notional amount. This means that the floating rate calculation replicates the accrual on an amount (principal plus interest) rolled at the index rate every business day over the term of the swap. If cash can be borrowed by the swap receiver on the same maturity as the swap and at the same rate and lent back every day in the market at the index rate, the cash payoff at maturity will exactly match the swap payout: the OIS acts as a perfect hedge for a cash instrument. Since indices are generally constructed on the basis of the average of actual transactions, the index is generally achievable by borrowers and lenders. Economically, receiving the fixed rate in an OIS is like lending cash. Paying the fixed rate in an OIS is like borrowing cash. Settlement occurs net on the earliest practical date. There is no exchange of principal. The index rate used is typically the weighted average rate for overnight transactions as published by the central bank (e.g., the effective fed funds rate).

Repo-Haircut Index: The equal-weighted average haircut for all nine of the asset classes in Panel D of Table I. Haircuts of 100\% (= no trade) are included in this average. (Table I, Panel D)

Repo-Rate Index: During the time that all asset classes have active repo markets in 2007 and early 2008, this index is identical to the equal-weighted average repo rate for all nine the asset classes in Panel D of Table I. As haircuts rise to $100 \%$ for any given asset class (= no trade) on date $t$, we drop that class from the index and compute the index change for period $t$ using only the classes that traded in both period $t-1$ and period $t$. (Table I, Panel D)

Repurchase Agreements (repo), Reverse Repurchase Agreements (reverse repo): A sale and repurchase agreement, known as a "repo" for short, is a sale of a security combined with an 
agreement to repurchase the same security at a specified price at the end of the contract. Economically, a repo is a secured or collateralized loan, that is, a loan of cash against a security as collateral. From the point of view of the borrower of the cash (who is putting up the security as collateral), it is a reverse repurchase agreement, or "reverse repo."

Residential Mortgage-backed Security (RMBS): See asset-backed securities, above.

Securitization: The process of financing by segregating specified cash flows, from loans originated by a firm (the "sponsor") and selling claims specifically linked to these specified cash flows. This is accomplished by setting up another company, called a special purpose vehicle (SPV) or special purpose entity, and then selling the specified cash flows to this company, which purchases the rights to the cash flows by issuing (rated) securities into the capital market. The sponsor services the cash flows, that is, makes sure that the cash flows are arriving, etc. The SPV is not an operating company in the usual sense. It is more of a robot company in that it is a set of rules. It has no employees or physical location.

Securitized Banking: Refers in this paper to the nexus of securitization and repurchase markets where "depositors" are able to engage in (reverse) repo by depositing money in exchange for securitized bonds as collateral.

Securitized Bonds: A general term referring to any traded and rated tranche of an ABS, RMBS, CMBS, CDO, or CLO.

Special Purpose Vehicle (SPV): An SPV or special purpose entity (SPE) is a legal entity which has been set up for a specific, limited, purpose by another entity, the sponsoring firm. An SPV can take the form of a corporation, trust, partnership, or a limited liability company. The SPV may be a subsidiary of the sponsoring firm, or it may be an "orphan" SPV, one that is not consolidated with the sponsoring firm for tax, accounting, or legal purposes (or may be consolidated for some purposes but not others). An SPV can only carry out some specific purpose, or circumscribed activity, or a series of such transactions. An essential feature of an SPV is that it be "bankruptcy remote," that is, that the SPV never be able to become legally bankrupt. The most straightforward way to achieve this would be for the SPV to waive its right to file a voluntary bankruptcy petition, but this is legally unenforceable. The only way to completely eliminate the risk of either voluntary or involuntary bankruptcy is to create the SPV in a legal form that is ineligible to be a debtor under the U.S. Bankruptcy Code. 
Structured Finance: A broad term used to describe securitized bonds, but also more generally any bond with an embedded derivative.

Student AAA: AAA-rated ABS backed by student loans. (Table I - Panel B)

Tranche: A tranche (French for "cut") refers to a slice of an portfolio ordered by seniority, e.g., a senior tranche or AAA tranche is more senior than a junior tranche or BBB-rated tranche.

Triparty Repo: A sale and repurchase agreement that is intermediated by a custodian bank of international clearing organization. The intermediary manages the transaction including marking-to-market of the collateral. Parties to the transaction agree to an eligible collateral profile which determines what bonds can be used as collateral. The intermediary bears intra-day risk; see Task Force on Tri-Party Infrastructure (2010).

UK Cards AAA: AAA-rated ABS backed by UK credit-card receivables (Table I - Panel C)

UK RMBS AAA: AAA-rated RMBS backed by UK mortgages. (Table I - Panel C)

Unpriced ABS/MBS, All Subprime: All tranches of ABS, MBS and all subprime securitized bonds which do not have public pricing posted on Bloomberg or Reuters (two news services used by traders) (Table I - Panel D)

Unpriced CDO/CLO: All tranches of CDO and CLO securitized bonds which do not have public pricing posted on Bloomberg or Reuters (two news services used by traders) (Table I Panel D)

VIX: The VIX index is a measure of the volatility of the S\&P index, produced by and traded on the Chicago Board of Trade. The new version of the index introduced in 2003, is based on the options prices of the broader S\&P 500 index. Its square approximates the conditional riskneutral expectation of the annualized return variance over the next 30 calendar days and thus the corresponding variance swap rate. See Carr and Wu (2006). (Table I - Panel E) 


\section{Appendix B: The Spread Data}

Spreads are not a common variable of analysis for financial economists, who prefer to focus on returns. As a practical matter, however, interest rate risk is frequently hedged, leaving credit risk as the focus. Credit spreads isolate the risk of default and the recovery rate. Thus, when assessing fixed income securities, investors focus on spreads as a common measure for determining how much they are being paid to bear the credit risk embedded in a security.

For fixed rate instruments, the spread is the yield spread, i.e., the difference between the yield-to-maturity of the credit risky instrument and the benchmark instrument (LIBOR) with the same maturity. Floating rate instrument prices are converted to a spreads by determining the discount margin, which is the fixed amount to be added to the current LIBOR rate that is required to reprice the bond to par. The discount margin measures the yield relative to the current LIBOR rate and so does not take into account the term structure of interest rates.

The discount margin, dm, satisfies the following relationship:

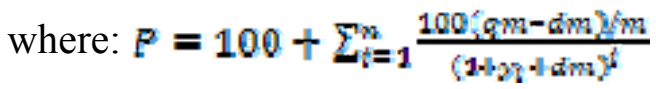

$$
\begin{aligned}
& \mathrm{P}=\text { Price of the floating rate note }(\mathrm{FRN}) \text { per } \$ 100 \text { face value; } \\
& \mathrm{qm}=\text { Quoted margin on FRN; } \\
& \mathrm{dm}=\text { discount margin; } \\
& \mathrm{y}_{\mathrm{i}}=\text { Assumed value of the reference rate (LIBOR) in period } \mathrm{i} \text {; } \\
& \mathrm{n}=\text { number of period until maturity; } \\
& \mathrm{m}=\text { number of period per year. }
\end{aligned}
$$

The formula shows that if the quoted margin is equal to the discount margin, then the second term is zero and the FRN is valued at par. If the current price of the floater differs from par, then the discount margin is nonzero. The discount margin assumes that the cash flows over the 
remaining life of the bond are determined by the current reference rate value. The margin is selected so that the present value of the cash flows is equal to the security's price. The discount margin is a measure which is similar to yield-to-maturity for fixed rate instruments. It expresses the price of an FRN relative to the current LIBOR level. See Fabozzi and Mann (2000). 


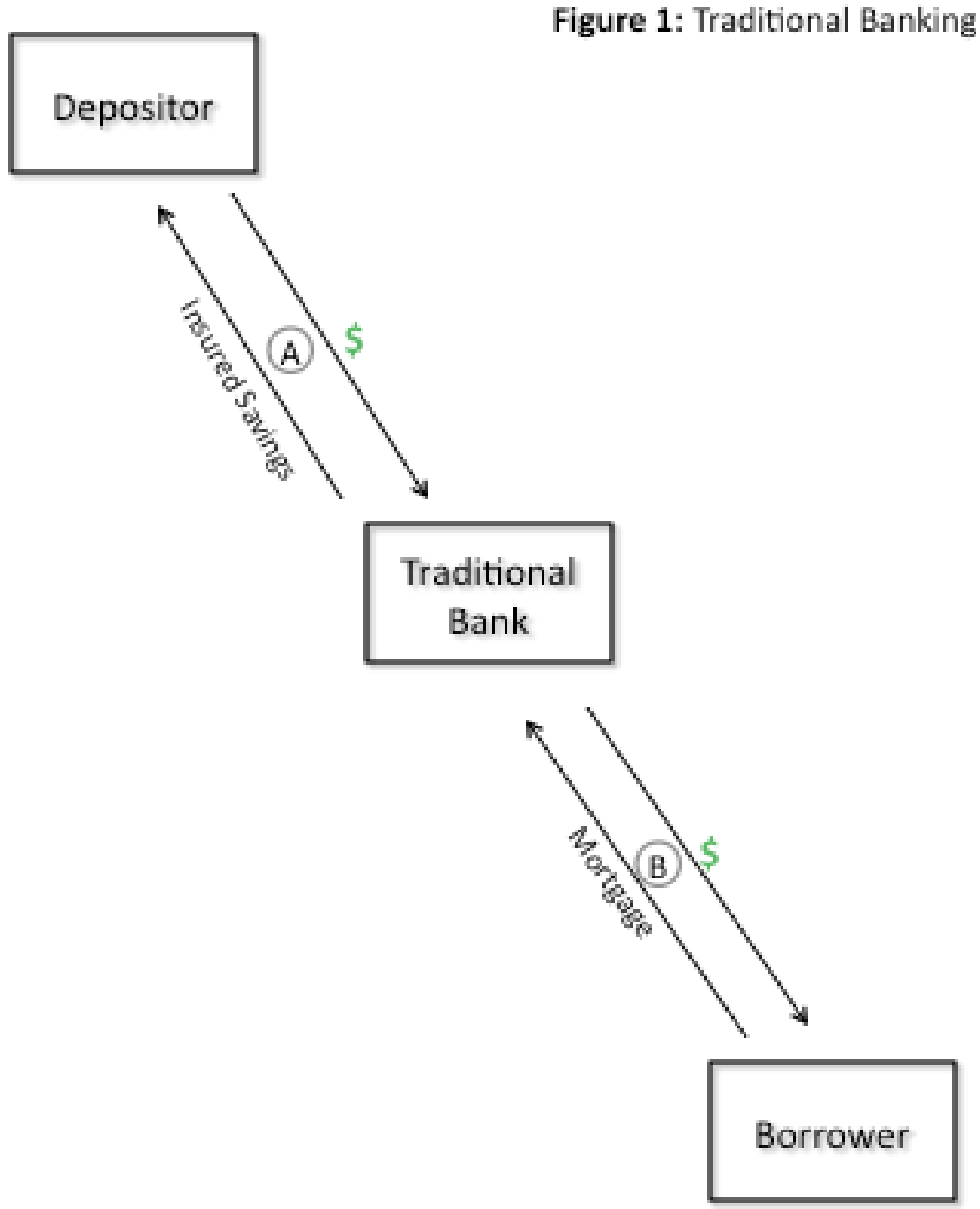


Figure 2: Securitized Banking

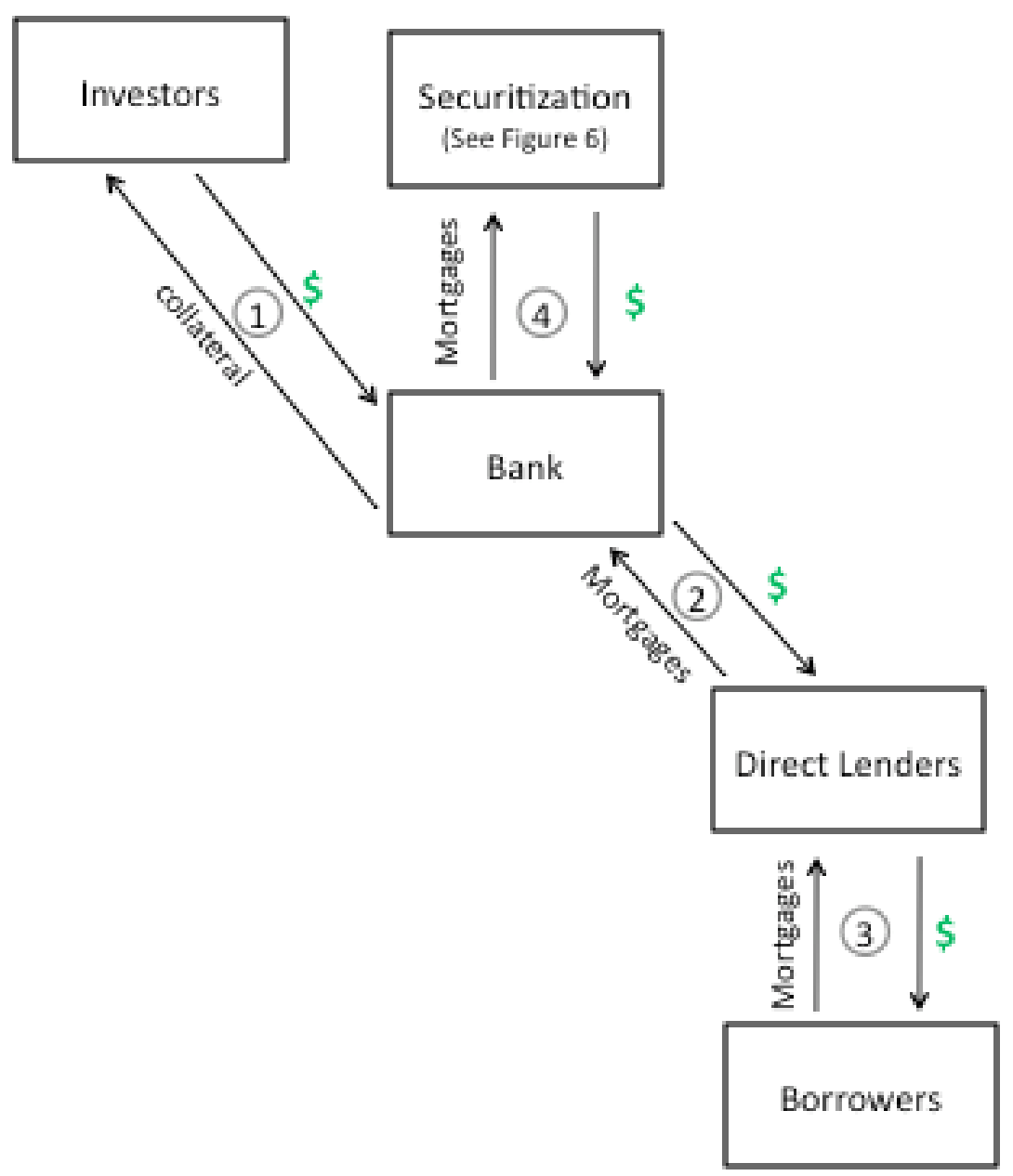




\section{Figure 3: Traditional Banking vs. Securitized Banking}

Traditional Banking

(1) Reserves

- Minimum levels set by regulators.

- Shortfalls can be borrowed from central bank.

(2) Deposit Insurance

- Guaranteed by the government

(3) Interest Rates on Deposits

- Can be raised to attract deposits when reserves are low.

(4) Loans Held on Balance Sheet
Securitized Banking

(1) Haircuts

- Minimum levels set by counterparties.

- No borrowing from central bank.

(2) Collateral

- Cash, treasury securities, loans, or securitized bonds

(3) Repo Rates

- Can be raised to attract counterparties when funds are low.

(4) Loans Securitized

- Some securitized bonds may be kept on balance sheet and used as collateral 
Figure 4: The Repo-Haircut Index

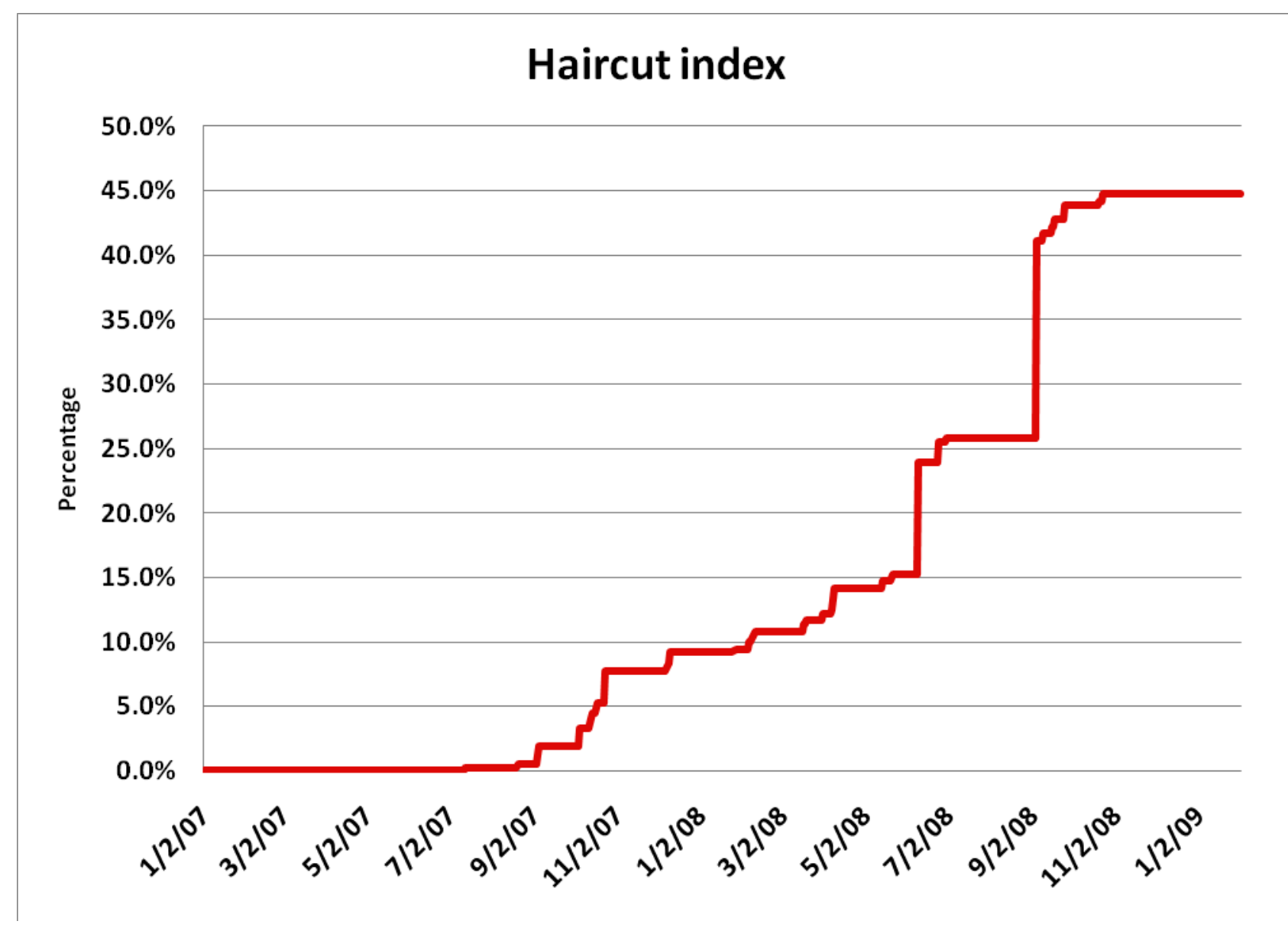

Notes: The repo-haircut index is the equally-weighted average haircut for all nine asset classes included in Table I, Panel D. 
Figure 5: Issuance in U.S. Capital Markets (\$ billions)

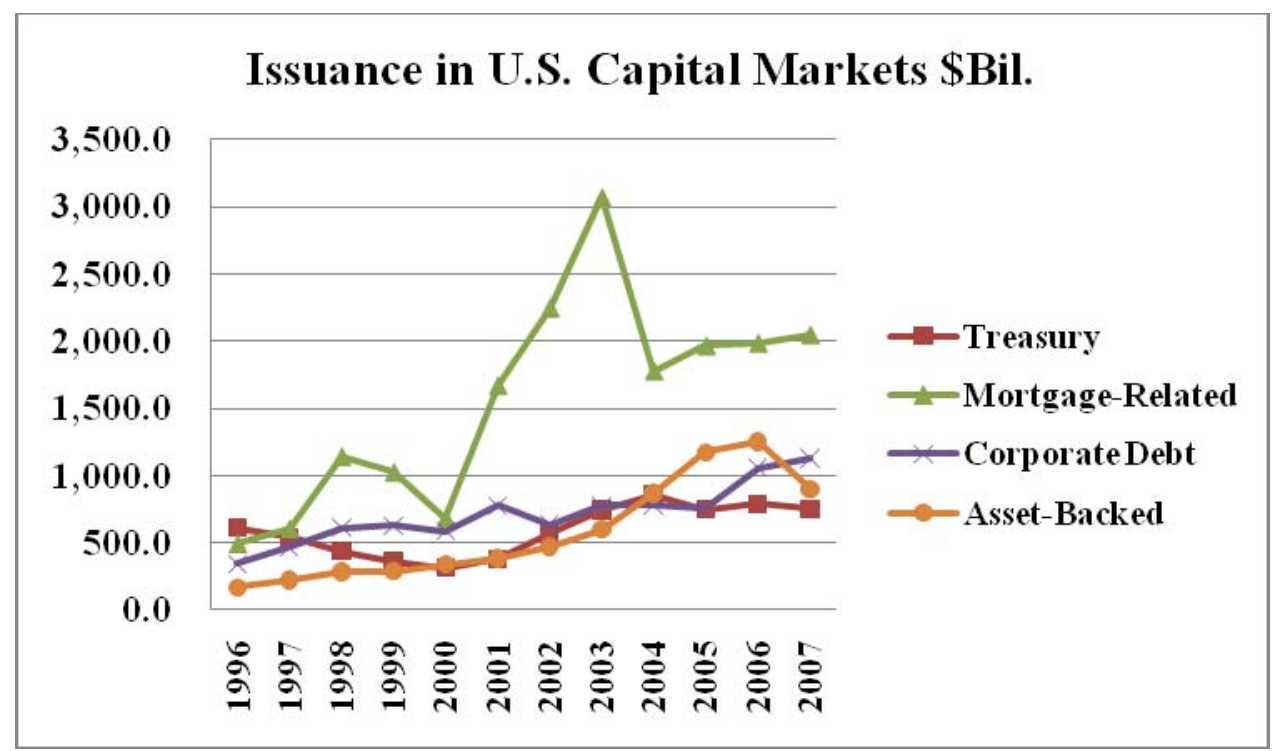

Sources: U.S. Department of Treasury, Federal Agencies, Thomson Financial, Inside MBS \& ABS, Bloomberg. 
Figure 6: Securitization

(continuation of Figure 2)

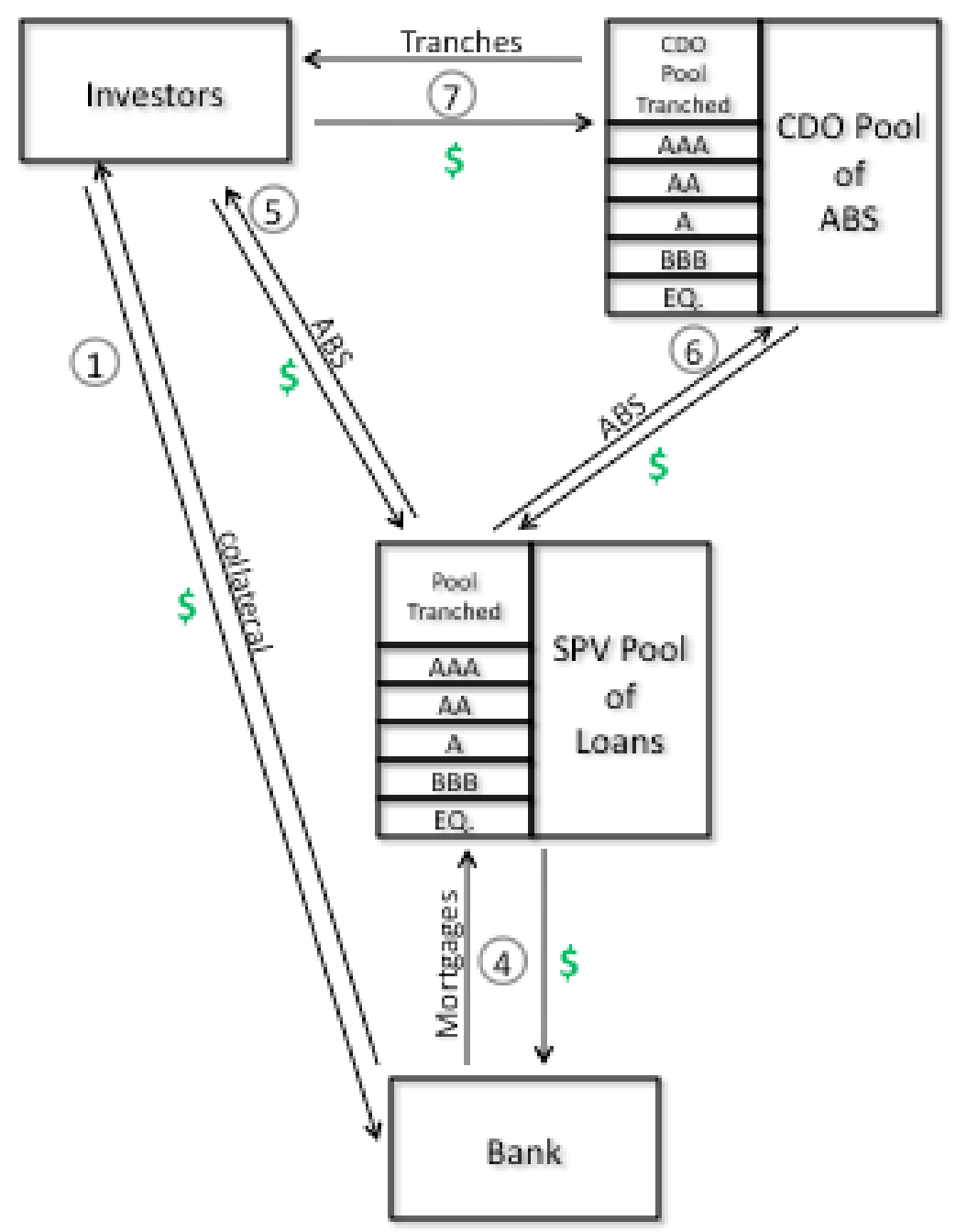


FIGURE 7

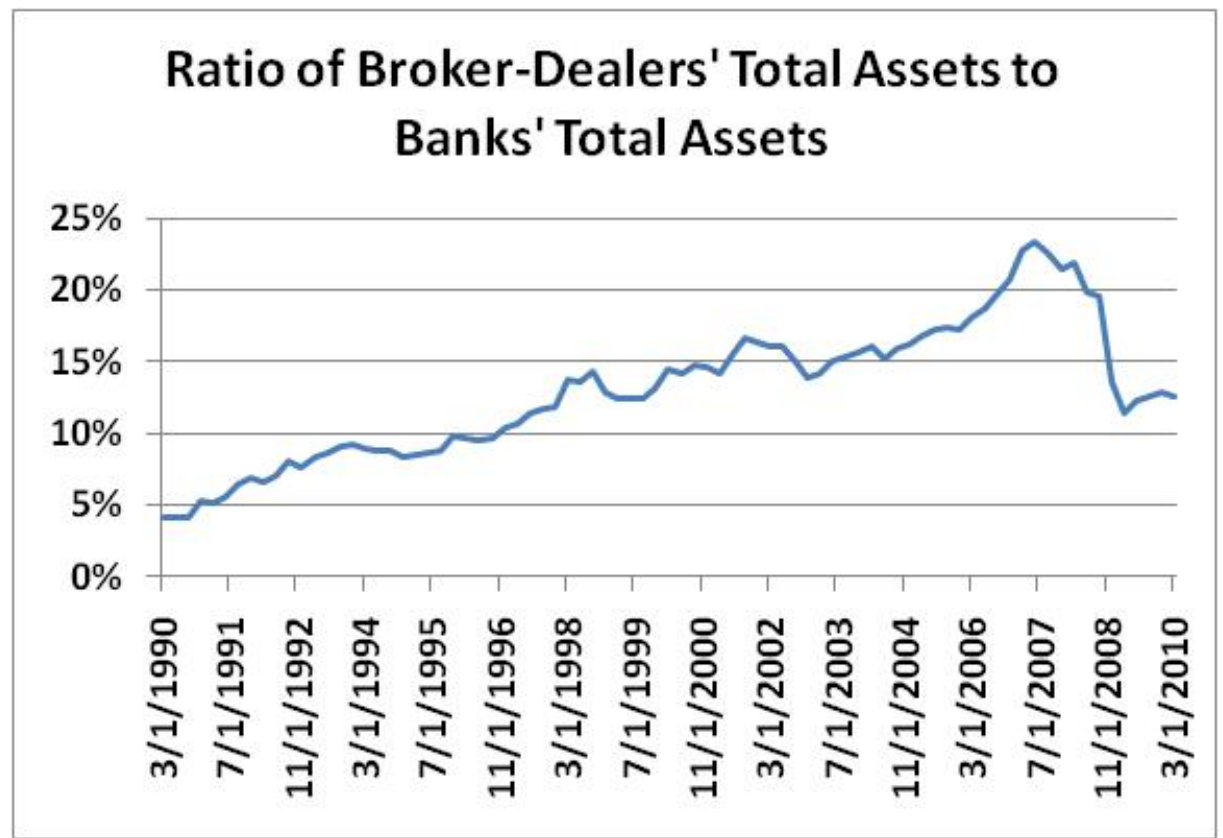

Source: Federal Flow of Funds. 
FIGURE 8: ABX vs. LIB-OIS

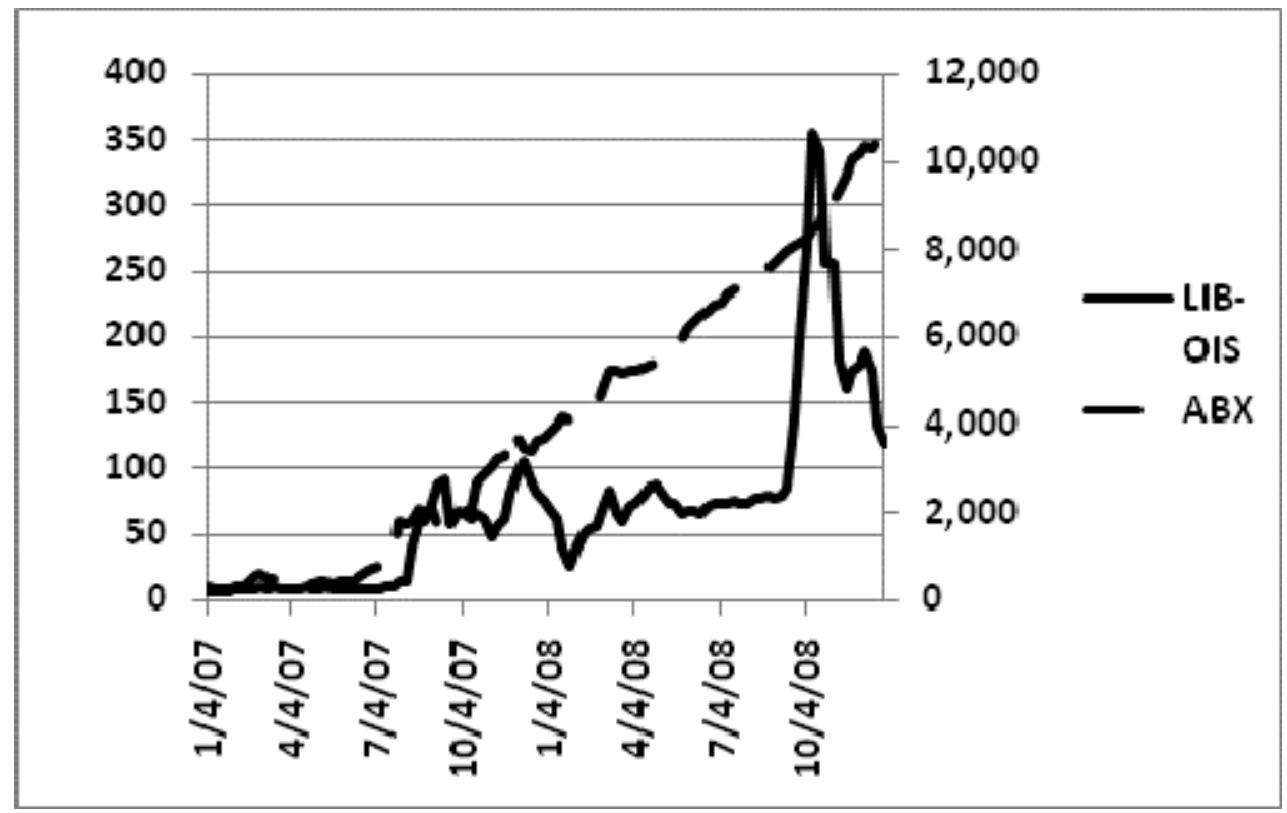

Notes: ABX is the 2006-1 BBB tranche. LIB-OIS spreads on left-hand Y-axis, ABX spreads on right-hand $\mathrm{y}$-axis. Both scales are in basis points. 
Figure 9: LIB-OIS and Non-Subprime-Related Asset Classes

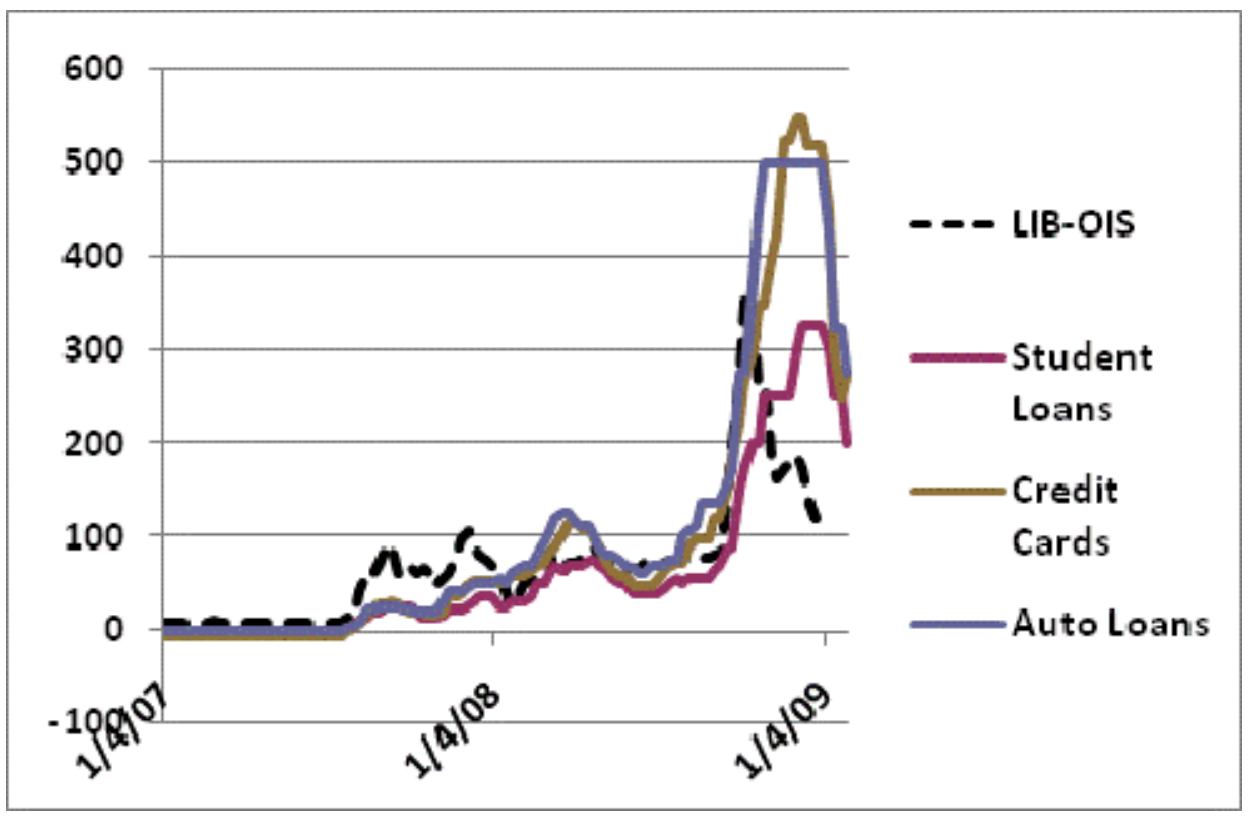

Notes: LIB-OIS is shown with the spreads on AAA-rated asset-backed securities: student loans, credit cards, and auto loans. The scale is in basis points. 
Table I: Broker-Dealer Repo Financing (\$ billions)

\begin{tabular}{lcccccc}
\hline Mid-2008 & GS & MS & LEH & ML & BSC & Sum \\
\hline Financial instruments owned & 411,194 & 390.393 & 269,409 & 288,925 & 141,104 & $1,501,025$ \\
$\quad$ of which pledged (and can be repledged) & 37,383 & 140,000 & 43,031 & 27,512 & 22,903 & 270,829 \\
$\quad$ of which pledged (and cannot be & & & & & & \\
& 120,980 & 54,492 & 80,000 & 53,025 & 54,000 & 362,497 \\
repledged) & 252,831 & 195,901 & 146,378 & 208,388 & 64,201 & 867,699 \\
$\quad$ of which not pledged at all & $38.5 \%$ & $49.8 \%$ & $45.7 \%$ & $27.9 \%$ & $54.5 \%$ & $42.2 \%$ \\
\% own financial instruments pledged &
\end{tabular}

Source: Company 10-Qs. See King (2008) and Aitken and Singh (2009).

\begin{tabular}{|c|c|c|c|c|c|c|c|c|}
\hline End of 2006 & GS & MS & LEH & ML & $\mathrm{BSC}$ & Sum & ML* & ML** \\
\hline Financial instruments owned & 334,561 & 380,853 & 226,596 & 312,187 & 125,168 & $1,379,365$ & 287,258 & 203,848 \\
\hline $\begin{array}{l}\text { of which pledged (and can be repledged) } \\
\text { of which pledged (and cannot be }\end{array}$ & 35,998 & 125,000 & 42,600 & 58,966 & 15,967 & 278,531 & 58,966 & 58,966 \\
\hline repledged) & 134,310 & 63,903 & 75,000 & 68,594 & 41,000 & 382,807 & 68,594 & 68,594 \\
\hline of which not pledged at all & 164,253 & 191,950 & 108,996 & 184,627 & 68,201 & 718,027 & 159,698 & 76,288 \\
\hline$\%$ own financial instruments pledged & $50.9 \%$ & $49.6 \%$ & $51.9 \%$ & $40.9 \%$ & $45.5 \%$ & $47.9 \%$ & $44.4 \%$ & $62.6 \%$ \\
\hline
\end{tabular}

Source: Company 10-Qs.

Merrill Lynch (ML) did not list "Financial instruments owned." Instead, ML listed "Trading assets," "Investment securities" and "Securities received as collateral". In the column ML, all three asset categories were used. In the column marked ML**, only Trading assets and Investment securities were included. In the case of $\mathrm{ML}^{* *}$, only Trading assets were used. 


\section{Table II \\ Summary Statistics}

This table reports the summary statistics for the state variable, credit spreads, repo spreads and control variables used in this paper. For each series we show summary statistics for the whole period and four subperiods. Panel A shows statistics for the state variable LIB-OIS and the credit spreads of three categories of subprime related assets. Panel B and Panel C shows statistics for the credit spreads of U.S. and non-U.S. non-subprime asset classes. Panel D reports the statistics for the spreads between three-month repo rates and OIS. Panel E shows statistics for the five control variables used in the regression analysis. All variables given in this Table are defined in Appendix A. All spreads are measured in basis points, with spread computations explained in Appendix B.

\begin{tabular}{|c|c|c|c|c|c|c|}
\hline & & & & Panel A: State Variable and Subprime Related Assets Class & & \\
\hline Series & Periods & Mean & Median & Std. Err. & Max & Min \\
\hline \multicolumn{7}{|c|}{ State Variable } \\
\hline \multirow{5}{*}{ LIB-OIS Spread } & Whole period & 72.43 & 66.44 & 67.57 & 354.20 & 7.45 \\
\hline & First half of 2007 & 7.97 & 7.88 & 0.42 & 9.15 & 7.45 \\
\hline & Second half of 2007 & 58.71 & 60.78 & 28.64 & 104.73 & 7.70 \\
\hline & All of 2007 & 33.34 & 8.50 & 32.53 & 104.73 & 7.45 \\
\hline & All of 2008 & 108.10 & 77.20 & 71.61 & 354.20 & 24.33 \\
\hline \multicolumn{7}{|c|}{ Credit Spreads of Sub-prime Related Assets } \\
\hline \multirow{4}{*}{ HEL BBB } & Whole period & 714.25 & 425.00 & 545.26 & 1800.00 & 170.00 \\
\hline & First half of 2007 & 273.27 & 250.00 & 93.54 & 425.00 & 170.00 \\
\hline & Second half of 2007 & 1113.46 & 1000.00 & 441.03 & 1800.00 & 350.00 \\
\hline & All of 2007 & 693.37 & 425.00 & 528.75 & 1800.00 & 170.00 \\
\hline \multirow{5}{*}{ Mezzanine CDO BBB } & Whole period & 2861.93 & 2969.42 & 2023.57 & 8421.76 & 365.00 \\
\hline & First half of 2007 & 627.50 & 650.00 & 152.50 & 950.00 & 365.00 \\
\hline & Second half of 2007 & 2178.47 & 1940.75 & 659.41 & 3063.16 & 1100.00 \\
\hline & All of 2007 & 1402.99 & 1025.00 & 915.27 & 3063.16 & 365.00 \\
\hline & All of 2008 & 4858.38 & 4687.97 & 1268.88 & 8421.76 & 3016.83 \\
\hline \multirow{4}{*}{ HELOC AAA } & Whole Period & 121.60 & 18.00 & 157.64 & 500.00 & 14.00 \\
\hline & First half of 2007 & 15.35 & 15.00 & 1.23 & 18.00 & 14.00 \\
\hline & Second half of 2007 & 213.31 & 195.00 & 159.59 & 500.00 & 15.00 \\
\hline & All of 2007 & 114.33 & 18.00 & 149.92 & 500.00 & 14.00 \\
\hline \multicolumn{7}{|c|}{ CDS Spreads of Subprime Mortgage Lenders } \\
\hline \multirow{5}{*}{ Countrywide } & Whole period & 275.86 & 220.02 & 253.96 & 1185.84 & 22.52 \\
\hline & First half of 2007 & 51.10 & 50.79 & 17.64 & 77.57 & 22.52 \\
\hline & Second half of 2007 & 445.43 & 282.34 & 338.99 & 1088.00 & 62.53 \\
\hline & All of 2007 & 248.26 & 71.09 & 310.03 & 1088.00 & 22.52 \\
\hline & All of 2008 & 301.04 & 260.00 & 188.39 & 1185.84 & 95.67 \\
\hline \multirow{5}{*}{ WAMU } & Whole period & 413.57 & 318.33 & 643.09 & 4352.43 & 19.61 \\
\hline & First half of 2007 & 35.39 & 33.68 & 11.11 & 57.38 & 19.61 \\
\hline & Second half of 2007 & 189.27 & 122.03 & 133.36 & 438.47 & 42.55 \\
\hline & All of 2007 & 112.33 & 50.32 & 121.71 & 438.47 & 19.61 \\
\hline & All of 2008 & 815.23 & 438.90 & 818.44 & 4352.43 & 255.00 \\
\hline \multicolumn{7}{|c|}{ CDS Spreads of Monoline Insurers } \\
\hline \multirow{5}{*}{ MBIA } & Whole period & 911.33 & 391.88 & 1116.88 & 4153.55 & 13.46 \\
\hline & First half of 2007 & 24.20 & 22.66 & 9.34 & 42.20 & 13.46 \\
\hline & Second half of 2007 & 164.92 & 121.69 & 89.44 & 322.96 & 45.18 \\
\hline & All of 2007 & 94.56 & 43.69 & 94.93 & 322.96 & 13.46 \\
\hline & All of 2008 & 1656.46 & 1391.26 & 1101.33 & 4153.55 & 372.55 \\
\hline \multirow{5}{*}{ MGIC } & Whole period & 520.96 & 453.46 & 406.35 & 1411.73 & 27.48 \\
\hline & First half of 2007 & 51.42 & 52.40 & 17.82 & 81.32 & 27.48 \\
\hline & Second half of 2007 & 270.97 & 245.95 & 138.90 & 528.53 & 71.21 \\
\hline & All of 2007 & 161.20 & 79.09 & 147.99 & 528.53 & 27.48 \\
\hline & All of 2008 & 849.17 & 885.61 & 262.06 & 1411.73 & 320.00 \\
\hline \multirow{5}{*}{ Radian } & Whole period & 1072.85 & 809.83 & 956.80 & 3164.27 & 28.53 \\
\hline & First half of 2007 & 56.54 & 55.49 & 18.12 & 93.39 & 28.53 \\
\hline & Second half of 2007 & 536.20 & 559.22 & 261.37 & 1000.32 & 73.26 \\
\hline & All of 2007 & 296.37 & 86.62 & 303.80 & 1000.32 & 28.53 \\
\hline & All of 2008 & 1781.22 & 1938.22 & 781.58 & 3164.27 & 704.70 \\
\hline
\end{tabular}




\begin{tabular}{|c|c|c|c|c|c|c|}
\hline \multicolumn{7}{|c|}{ Panel B:U.S. Non-Subprime Asset Classes } \\
\hline Series & Periods & Mean & Median & Std. Err. & Max & Min \\
\hline \multirow{5}{*}{ Auto AAA } & Whole period & 109.42 & 55.00 & 153.65 & 500.00 & -1.00 \\
\hline & First half of 2007 & -1.00 & -1.00 & 0.00 & -1.00 & -1.00 \\
\hline & Second half of 2007 & 23.38 & 20.00 & 16.11 & 50.00 & -1.00 \\
\hline & All of 2007 & 11.19 & -1.00 & 16.70 & 50.00 & -1.00 \\
\hline & All of 2008 & 199.04 & 110.00 & 167.75 & 500.00 & 50.00 \\
\hline \multirow{5}{*}{ Cards AAA } & Whole period & 101.92 & 55.00 & 148.93 & 550.00 & -4.00 \\
\hline & First half of 2007 & -3.31 & -3.00 & 0.47 & -3.00 & -4.00 \\
\hline & Second half of 2007 & 24.88 & 23.00 & 17.73 & 55.00 & -3.00 \\
\hline & All of 2007 & 10.79 & -3.00 & 18.89 & 55.00 & -4.00 \\
\hline & All of 2008 & 185.05 & 100.00 & 166.45 & 550.00 & 50.00 \\
\hline \multirow{5}{*}{ Student AAA } & Whole period & 65.11 & 30.00 & 90.47 & 325.00 & -3.00 \\
\hline & First half of 2007 & -1.12 & -1.00 & 1.18 & 0.00 & -3.00 \\
\hline & Second half of 2007 & 17.92 & 18.00 & 10.28 & 35.00 & 0.00 \\
\hline & All of 2007 & 8.40 & 0.00 & 12.03 & 35.00 & -3.00 \\
\hline & All of 2008 & 116.84 & 65.00 & 99.71 & 325.00 & 25.00 \\
\hline \multirow{5}{*}{ CMBS AAA } & Whole period & 241.16 & 123.00 & 313.92 & 1350.00 & 22.00 \\
\hline & First half of 2007 & 26.27 & 26.50 & 2.79 & 31.00 & 22.00 \\
\hline & Second half of 2007 & 65.88 & 62.00 & 21.83 & 105.00 & 31.50 \\
\hline & All of 2007 & 46.08 & 31.25 & 25.25 & 105.00 & 22.00 \\
\hline & All of 2008 & 419.12 & 250.00 & 349.14 & 1350.00 & 83.00 \\
\hline \multirow{5}{*}{ HG SF CDO AAA } & Whole period & 482.24 & 428.32 & 424.87 & 1463.10 & 23.00 \\
\hline & First half of 2007 & 23.73 & 23.00 & 2.68 & 35.00 & 23.00 \\
\hline & Second half of 2007 & 177.88 & 108.09 & 135.50 & 450.90 & 42.00 \\
\hline & All of 2007 & 100.81 & 38.50 & 122.72 & 450.90 & 23.00 \\
\hline & All of 2008 & 830.22 & 849.77 & 275.79 & 1463.10 & 391.43 \\
\hline \multirow{5}{*}{ Mezzanine SF CDO AAA } & Whole period & 1094.17 & 1084.79 & 873.46 & 2712.79 & 32.00 \\
\hline & First half of 2007 & 54.38 & 55.00 & 20.99 & 105.00 & 32.00 \\
\hline & Second half of 2007 & 567.96 & 444.69 & 380.54 & 1084.79 & 115.00 \\
\hline & All of 2007 & 311.17 & 110.00 & 372.07 & 1084.79 & 32.00 \\
\hline & All of 2008 & 1808.49 & 1742.65 & 506.59 & 2712.79 & 1006.25 \\
\hline \multicolumn{7}{|c|}{ Panel C: Non-US Non-Subprime Asset Classes } \\
\hline \multirow{5}{*}{ Australia RMBS AAA } & Whole period & 145.60 & 90.00 & 151.22 & 650.00 & 5.00 \\
\hline & First half of 2007 & 6.23 & 7.00 & 0.91 & 7.00 & 5.00 \\
\hline & Second half of 2007 & 48.15 & 50.00 & 24.66 & 90.00 & 5.00 \\
\hline & All of 2007 & 27.19 & 7.00 & 27.32 & 90.00 & 5.00 \\
\hline & All of 2008 & 257.55 & 200.00 & 133.86 & 650.00 & 90.00 \\
\hline \multirow{5}{*}{ UK RMBS AAA } & Whole period & 124.53 & 80.00 & 131.25 & 440.00 & 4.00 \\
\hline & First half of 2007 & 4.96 & 5.00 & 0.72 & 6.00 & 4.00 \\
\hline & Second half of 2007 & 45.15 & 50.00 & 22.23 & 80.00 & 5.00 \\
\hline & All of 2007 & 25.06 & 6.00 & 25.58 & 80.00 & 4.00 \\
\hline & All of 2008 & 218.58 & 180.00 & 121.08 & 440.00 & 80.00 \\
\hline \multirow{5}{*}{ Dutch RMBS AAA } & Whole Period & 56.56 & 50.00 & 42.40 & 170.00 & 10.00 \\
\hline & First half of 2007 & 10.69 & 11.00 & 0.74 & 12.00 & 10.00 \\
\hline & Second half of 2007 & 40.35 & 39.00 & 18.96 & 70.00 & 11.00 \\
\hline & All of 2007 & 25.52 & 12.00 & 20.02 & 70.00 & 10.00 \\
\hline & All of 2008 & 97.95 & 90.00 & 25.38 & 170.00 & 60.00 \\
\hline \multirow{5}{*}{ UK Cards AAA } & Whole period & 178.62 & 150.00 & 176.97 & 625.00 & 10.00 \\
\hline & First half of 2007 & 10.08 & 10.00 & 0.28 & 11.00 & 10.00 \\
\hline & Second half of 2007 & 44.38 & 40.00 & 25.94 & 90.00 & 11.00 \\
\hline & All of 2007 & 32.95 & 27.00 & 26.67 & 90.00 & 10.00 \\
\hline & All of 2008 & 281.91 & 215.00 & 165.05 & 625.00 & 90.00 \\
\hline \multirow{5}{*}{$\begin{array}{l}\text { European Consumer Receivable } \\
\text { AAA }\end{array}$} & Whole period & 206.25 & 200.00 & 176.36 & 600.00 & 15.00 \\
\hline & First half of 2007 & 15.29 & 15.00 & 0.76 & 17.00 & 15.00 \\
\hline & Second half of 2007 & 54.92 & 55.00 & 25.05 & 95.00 & 18.00 \\
\hline & All of 2007 & 46.52 & 50.00 & 27.59 & 95.00 & 15.00 \\
\hline & All of 2008 & 302.09 & 235.00 & 157.19 & 600.00 & 95.00 \\
\hline \multirow{5}{*}{ European Auto AAA } & Whole period & 120.57 & 85.00 & 119.56 & 450.00 & 7.00 \\
\hline & First half of 2007 & 7.14 & 7.00 & 0.38 & 8.00 & 7.00 \\
\hline & Second half of 2007 & 37.31 & 35.00 & 18.62 & 65.00 & 8.00 \\
\hline & All of 2007 & 30.91 & 30.00 & 20.68 & 65.00 & 7.00 \\
\hline & All of 2008 & 174.36 & 115.00 & 122.14 & 450.00 & 60.00 \\
\hline
\end{tabular}




\begin{tabular}{|c|c|c|c|c|c|c|c|}
\hline \multicolumn{8}{|c|}{ Panel D: Repo Rate Spreads (bps; except repo haircuts) } \\
\hline Series & Periods & Mean & Median & Std. Err. & Max & Min & $\begin{array}{l}\text { Mean of } \\
\text { Haircut }\end{array}$ \\
\hline \multirow{5}{*}{$\mathrm{BBB}+/ \mathrm{A}$ Corporates } & Whole period & 86.50 & 82.14 & 83.15 & 429.43 & 0.50 & $0.5 \%$ \\
\hline & First half of 2007 & 2.01 & 1.95 & 0.61 & 5.30 & 0.50 & $0.0 \%$ \\
\hline & Second half of 2007 & 61.85 & 65.49 & 36.29 & 126.35 & 1.70 & $0.0 \%$ \\
\hline & All of 2007 & 32.28 & 2.70 & 39.53 & 126.35 & 0.50 & $0.0 \%$ \\
\hline & All of 2008 & 136.19 & 103.63 & 81.61 & 429.43 & 44.33 & $0.9 \%$ \\
\hline \multirow{5}{*}{ AA-AAA Corporates } & Whole period & 77.59 & 74.78 & 78.42 & 409.43 & -3.50 & $0.5 \%$ \\
\hline & First half of 2007 & -1.69 & -2.05 & 1.90 & 10.44 & -3.50 & $0.0 \%$ \\
\hline & Second half of 2007 & 55.27 & 58.95 & 34.53 & 116.35 & -2.30 & $0.0 \%$ \\
\hline & All of 2007 & 27.13 & -1.35 & 37.64 & 116.35 & -3.50 & $0.0 \%$ \\
\hline & All of 2008 & 123.86 & 92.11 & 77.57 & 409.43 & 39.33 & $0.9 \%$ \\
\hline \multirow{5}{*}{$\begin{array}{c}\text { A-AAA ABS-Auto / CC } \\
\text { / SL }\end{array}$} & Whole period & 105.22 & 94.76 & 101.00 & 479.43 & 1.70 & $5.2 \%$ \\
\hline & First half of 2007 & 4.44 & 4.00 & 1.77 & 11.00 & 1.70 & $0.0 \%$ \\
\hline & Second half of 2007 & 68.44 & 71.78 & 40.93 & 141.35 & 3.70 & $0.9 \%$ \\
\hline & All of 2007 & 36.82 & 5.25 & 43.29 & 141.35 & 1.70 & $0.5 \%$ \\
\hline & All of 2008 & 167.92 & 119.81 & 98.07 & 479.43 & 54.33 & $9.5 \%$ \\
\hline \multirow{5}{*}{$\begin{array}{c}\text { AA-AAA ABS-RMBS / } \\
\text { CMBS }\end{array}$} & Whole period & 124.04 & 107.78 & 120.11 & 520.30 & 3.70 & $9.4 \%$ \\
\hline & First half of 2007 & 6.41 & 6.00 & 1.76 & 13.00 & 3.70 & $0.0 \%$ \\
\hline & Second half of 2007 & 76.35 & 81.78 & 43.92 & 151.35 & 5.70 & $1.8 \%$ \\
\hline & All of 2007 & 41.80 & 7.00 & 46.92 & 151.35 & 3.70 & $0.9 \%$ \\
\hline & All of 2008 & 199.44 & 145.08 & 117.27 & 520.30 & 64.33 & $17.1 \%$ \\
\hline \multirow{5}{*}{$\begin{array}{c}<\mathrm{AA} \text { ABS-RMBS / } \\
\text { CMBS }\end{array}$} & Whole period & 135.90 & 117.78 & 129.02 & 550.30 & 6.70 & $10.6 \%$ \\
\hline & First half of 2007 & 9.41 & 9.00 & 1.76 & 16.00 & 6.70 & $0.0 \%$ \\
\hline & Second half of 2007 & 84.55 & 88.20 & 48.62 & 166.35 & 8.70 & $3.7 \%$ \\
\hline & All of 2007 & 47.43 & 10.00 & 51.08 & 166.35 & 6.70 & $1.9 \%$ \\
\hline & All of 2008 & 217.01 & 153.95 & 125.56 & 550.30 & 69.33 & $18.6 \%$ \\
\hline \multirow{5}{*}{$\begin{array}{l}\text { Unpriced ABS / MBS / } \\
\text { All Sub-Prime }\end{array}$} & Whole period & 108.94 & 109.69 & 84.64 & 295.38 & 7.70 & $37.3 \%$ \\
\hline & First half of 2007 & 10.41 & 10.00 & 1.76 & 17.00 & 7.70 & $0.0 \%$ \\
\hline & Second half of 2007 & 95.62 & 97.83 & 58.54 & 196.35 & 9.70 & $7.7 \%$ \\
\hline & All of 2007 & 53.52 & 11.00 & 59.59 & 196.35 & 7.70 & $3.9 \%$ \\
\hline & All of 2008 & 187.28 & 197.88 & 42.23 & 295.38 & 99.33 & $68.0 \%$ \\
\hline \multirow{5}{*}{ AA-AAA CLO } & Whole period & 134.46 & 117.14 & 127.18 & 545.30 & 3.70 & $10.2 \%$ \\
\hline & First half of 2007 & 6.41 & 6.00 & 1.76 & 13.00 & 3.70 & $0.0 \%$ \\
\hline & Second half of 2007 & 85.93 & 92.65 & 51.27 & 171.35 & 5.70 & $1.8 \%$ \\
\hline & All of 2007 & 46.64 & 7.00 & 53.98 & 171.35 & 3.70 & $0.9 \%$ \\
\hline & All of 2008 & 214.96 & 148.76 & 121.61 & 545.30 & 79.33 & $18.7 \%$ \\
\hline \multirow{5}{*}{ AA-AAA CDO } & Whole period & 130.09 & 124.69 & 107.46 & 380.38 & 4.70 & $30.0 \%$ \\
\hline & First half of 2007 & 7.41 & 7.00 & 1.76 & 14.00 & 4.70 & $0.0 \%$ \\
\hline & Second half of 2007 & 107.77 & 109.35 & 69.56 & 226.35 & 6.70 & $8.3 \%$ \\
\hline & All of 2007 & 58.19 & 8.00 & 70.48 & 226.35 & 4.70 & $4.3 \%$ \\
\hline & All of 2008 & 231.72 & 241.39 & 56.52 & 380.38 & 129.33 & $53.5 \%$ \\
\hline \multirow{5}{*}{ Unpriced CLO / CDO } & Whole period & 148.32 & 142.60 & 123.54 & 413.75 & 6.70 & $32.4 \%$ \\
\hline & First half of 2007 & 9.41 & 9.00 & 1.76 & 16.00 & 6.70 & $0.0 \%$ \\
\hline & Second half of 2007 & 122.63 & 124.42 & 80.14 & 256.35 & 8.70 & $10.5 \%$ \\
\hline & All of 2007 & 66.69 & 10.00 & 80.34 & 256.35 & 6.70 & $5.4 \%$ \\
\hline & All of 2008 & 268.39 & 256.58 & 63.03 & 413.75 & 154.33 & $57.3 \%$ \\
\hline \multirow{5}{*}{$\begin{array}{l}\text { Repo-Rate Index and } \\
\text { Repo-Haircut Index (last } \\
\text { column) }\end{array}$} & Whole period & 151.36 & 130.89 & 152.79 & 688.10 & 3.81 & $15.1 \%$ \\
\hline & First half of 2007 & 6.03 & 5.67 & 1.45 & 11.33 & 3.81 & $0.0 \%$ \\
\hline & Second half of 2007 & 84.27 & 89.18 & 51.14 & 172.46 & 5.37 & $3.9 \%$ \\
\hline & All of 2007 & 45.61 & 6.98 & 53.44 & 172.46 & 3.81 & $2.0 \%$ \\
\hline & All of 2008 & 248.29 & 171.20 & 149.95 & 688.10 & 81.55 & $27.2 \%$ \\
\hline
\end{tabular}




\begin{tabular}{|c|c|c|c|c|c|c|}
\hline \multicolumn{7}{|c|}{ Panel E: Control variables } \\
\hline Series & Periods & Mean & Median & Std. Err. & Max & Min \\
\hline \multirow{5}{*}{ ABX Index (bps) } & Whole period & 4090.11 & 3604.00 & 3524.76 & 10940.98 & 121.00 \\
\hline & First half of 2007 & 302.15 & 329.50 & 139.54 & 552.00 & 121.00 \\
\hline & Second half of 2007 & 1657.69 & 1752.00 & 894.91 & 3286.00 & 368.00 \\
\hline & All of 2007 & 979.92 & 481.50 & 933.01 & 3286.00 & 121.00 \\
\hline & All of 2008 & 6927.48 & 6938.67 & 2447.64 & 10940.98 & 3373.00 \\
\hline \multirow{5}{*}{ 10Year Treasury Rate } & Whole period & $4.07 \%$ & $4.04 \%$ & $0.71 \%$ & $5.19 \%$ & $2.08 \%$ \\
\hline & First half of 2007 & $4.77 \%$ & $4.73 \%$ & $0.20 \%$ & $5.19 \%$ & $4.51 \%$ \\
\hline & Second half of 2007 & $4.52 \%$ & $4.51 \%$ & $0.32 \%$ & $5.14 \%$ & $3.96 \%$ \\
\hline & All of 2007 & $4.64 \%$ & $4.66 \%$ & $0.29 \%$ & $5.19 \%$ & $3.96 \%$ \\
\hline & All of 2008 & $3.56 \%$ & $3.72 \%$ & $0.56 \%$ & $4.50 \%$ & $2.08 \%$ \\
\hline \multirow{5}{*}{ OIS } & Whole period & $3.26 \%$ & $3.53 \%$ & $1.79 \%$ & $5.29 \%$ & $0.18 \%$ \\
\hline & First half of 2007 & $5.28 \%$ & $5.28 \%$ & $0.01 \%$ & $5.29 \%$ & $5.26 \%$ \\
\hline & Second half of 2007 & $4.65 \%$ & $4.60 \%$ & $0.42 \%$ & $5.28 \%$ & $4.07 \%$ \\
\hline & All of 2007 & $4.96 \%$ & $5.27 \%$ & $0.43 \%$ & $5.29 \%$ & $4.07 \%$ \\
\hline & All of 2008 & $1.70 \%$ & $2.00 \%$ & $0.94 \%$ & $3.96 \%$ & $0.18 \%$ \\
\hline \multirow{5}{*}{ Return of S\&P 500} & Whole period & $-0.40 \%$ & $0.20 \%$ & $3.83 \%$ & $17.97 \%$ & $-18.34 \%$ \\
\hline & First half of 2007 & $0.25 \%$ & $0.18 \%$ & $1.45 \%$ & $3.04 \%$ & $-3.65 \%$ \\
\hline & Second half of 2007 & $-0.06 \%$ & $0.01 \%$ & $2.02 \%$ & $3.74 \%$ & $-4.53 \%$ \\
\hline & All of 2007 & $0.09 \%$ & $0.18 \%$ & $1.75 \%$ & $3.74 \%$ & $-4.53 \%$ \\
\hline & All of 2008 & $-0.85 \%$ & $0.22 \%$ & $4.98 \%$ & $17.97 \%$ & $-18.34 \%$ \\
\hline \multirow{5}{*}{ VIX } & Whole period & 25.94 & 22.49 & 14.93 & 80.86 & 10.18 \\
\hline & First half of 2007 & 13.05 & 13.07 & 1.97 & 17.06 & 10.18 \\
\hline & Second half of 2007 & 21.88 & 21.2 & 4.02 & 30.83 & 15.23 \\
\hline & All of 2007 & 17.47 & 15.68 & 5.45 & 30.83 & 10.18 \\
\hline & All of 2008 & 33.68 & 25.59 & 16.59 & 80.86 & 16.3 \\
\hline \multirow{5}{*}{ Slope of Yield Curve } & Whole period & $1.01 \%$ & $1.22 \%$ & $0.78 \%$ & $2.62 \%$ & $-0.13 \%$ \\
\hline & First half of 2007 & $-0.02 \%$ & $-0.04 \%$ & $0.09 \%$ & $0.22 \%$ & $-0.13 \%$ \\
\hline & Second half of 2007 & $0.59 \%$ & $0.55 \%$ & $0.31 \%$ & $1.39 \%$ & $0.17 \%$ \\
\hline & All of 2007 & $0.29 \%$ & $0.18 \%$ & $0.38 \%$ & $1.39 \%$ & $-0.13 \%$ \\
\hline & All of 2008 & $1.66 \%$ & $1.57 \%$ & $0.34 \%$ & $2.62 \%$ & $1.08 \%$ \\
\hline
\end{tabular}




\section{Table III}

\section{Credit Spreads Regression Results}

For each bond i, we estimate equation (2) using weekly data from January 4, 2007 to January 29, 2009, $\Delta$ LIB-OIS is the percentage change of the spread between the 3-month LIBOR and the Overnight Index Swap (OIS). $\triangle \mathrm{ABX}$ is the parentage change of the ABX index at period t. $\triangle$ OIS is the Overnight Index Swap. $\Delta r-10$ is the change in yield on the 10-year Treasury, with its square given by $(\Delta \mathrm{r}-10)^{\wedge} 2 . \Delta$ Slope is the change in 10-year minus 2-year Treasury yields. $\Delta$ VIX is the change in implied volatility of S\&P 500, and $\Delta$ S\&P is the return on S\&P 500. t-statistics are given in parentheses below the coefficient estimates. The last two rows report F-statistics and p-values for the key state variables. The null hypothesis of the LIB-OIS F-Test is that the sum of all coefficients of $\Delta$ LIB-OIS and its lags is zero. The null hypothesis of the ABX F-Test is the sum of all coefficients of $\triangle \mathrm{ABX}$ and its lags is zero. Panel A shows the results of six U.S. non-subprime assets and Panel B shows the results of six non-US non-subprime assets.

\begin{tabular}{|c|c|c|c|c|c|c|}
\hline \multicolumn{7}{|c|}{ Panel A: U.S. Non-Subprime Asset Classes } \\
\hline & \multicolumn{6}{|c|}{$\begin{array}{l}\text { Credit Spreads } \\
\end{array}$} \\
\hline & Cards & Auto & Student & CMBS & $\begin{array}{c}\text { HG SF } \\
\text { CDO }\end{array}$ & $\begin{array}{c}\text { Mezz SF } \\
\text { CDO }\end{array}$ \\
\hline Intercept & $\begin{array}{l}0.003 \\
(0.1)\end{array}$ & $\begin{array}{l}0.016 \\
(0.33)\end{array}$ & $\begin{array}{l}-0.010 \\
(-0.33)\end{array}$ & $\begin{array}{l}0.036 \\
(2.41)\end{array}$ & $\begin{array}{l}0.042 \\
(2.86)\end{array}$ & $\begin{array}{l}0.052 \\
(3.96)\end{array}$ \\
\hline$\Delta \mathrm{LIB}-\mathrm{OIS}$ & $\begin{array}{l}0.341 \\
(3.24)\end{array}$ & $\begin{array}{l}0.079 \\
(0.54)\end{array}$ & $\begin{array}{l}0.461 \\
(5.23)\end{array}$ & $\begin{array}{l}0.025 \\
(0.26)\end{array}$ & $\begin{array}{l}-0.051 \\
(-1.16)\end{array}$ & $\begin{array}{l}-0.037 \\
(-0.94)\end{array}$ \\
\hline$\Delta$ LIB-OIS, t-1 & $\begin{array}{l}0.264 \\
(2.64)\end{array}$ & $\begin{array}{l}0.486 \\
(3.55)\end{array}$ & $\begin{array}{l}0.131 \\
(1.59)\end{array}$ & $\begin{array}{l}0.078 \\
(0.84)\end{array}$ & $\begin{array}{l}-0.042 \\
(-1.00)\end{array}$ & $\begin{array}{l}0.055 \\
(1.45)\end{array}$ \\
\hline$\Delta$ LIB-OIS, t-2 & $\begin{array}{l}0.132 \\
(1.32)\end{array}$ & $\begin{array}{l}0.012 \\
(0.08)\end{array}$ & $\begin{array}{l}0.138 \\
(1.67)\end{array}$ & $\begin{array}{l}-0.082 \\
(-0.92)\end{array}$ & $\begin{array}{l}0.038 \\
(0.91)\end{array}$ & $\begin{array}{l}-0.081 \\
(-2.15)\end{array}$ \\
\hline$\Delta$ LIB-OIS, t-3 & $\begin{array}{l}0.027 \\
(0.27)\end{array}$ & $\begin{array}{l}0.170 \\
(1.25)\end{array}$ & $\begin{array}{l}-0.013 \\
(-0.16)\end{array}$ & $\begin{array}{l}-0.030 \\
(-0.33)\end{array}$ & $\begin{array}{l}-0.030 \\
(-0.72)\end{array}$ & $\begin{array}{c}-0.004 \\
(-0.1)\end{array}$ \\
\hline$\triangle \mathrm{ABX}$ & $\begin{array}{l}-0.141 \\
(-0.66)\end{array}$ & $\begin{array}{l}-0.331 \\
(-1.13)\end{array}$ & $\begin{array}{l}0.455 \\
(2.32)\end{array}$ & $\begin{array}{l}0.012 \\
(0.27)\end{array}$ & $\begin{array}{l}0.001 \\
(0.00)\end{array}$ & $\begin{array}{l}0.070 \\
(0.86)\end{array}$ \\
\hline$\Delta \mathrm{ABX}, \mathrm{t}-1$ & $\begin{array}{l}0.079 \\
(0.36)\end{array}$ & $\begin{array}{l}-0.025 \\
(-0.09)\end{array}$ & $\begin{array}{c}0.119 \\
(0.6)\end{array}$ & $\begin{array}{l}-0.013 \\
(-0.32)\end{array}$ & $\begin{array}{l}0.016 \\
(0.18)\end{array}$ & $\begin{array}{l}0.061 \\
(0.74)\end{array}$ \\
\hline$\triangle \mathrm{ABX}, \mathrm{t}-2$ & $\begin{array}{l}0.315 \\
(1.48)\end{array}$ & $\begin{array}{l}0.250 \\
(0.86)\end{array}$ & $\begin{array}{l}-0.202 \\
(-1.06)\end{array}$ & $\begin{array}{l}-0.072 \\
(-1.71)\end{array}$ & $\begin{array}{l}-0.020 \\
(-0.23)\end{array}$ & $\begin{array}{c}-0.040 \\
(-0.5)\end{array}$ \\
\hline$\triangle \mathrm{ABX}, \mathrm{t}-3$ & $\begin{array}{l}-0.277 \\
(-1.3)\end{array}$ & $\begin{array}{c}-0.351 \\
(-1.2)\end{array}$ & $\begin{array}{l}-0.150 \\
(-0.69)\end{array}$ & $\begin{array}{l}-0.052 \\
(-1.24)\end{array}$ & $\begin{array}{l}0.049 \\
(0.54)\end{array}$ & $\begin{array}{l}-0.011 \\
(-0.14)\end{array}$ \\
\hline$\Delta \mathrm{OIS}$ & $\begin{array}{l}-0.253 \\
(-0.78)\end{array}$ & $\begin{array}{l}-0.147 \\
(-0.33)\end{array}$ & $\begin{array}{l}-0.358 \\
(-1.34)\end{array}$ & $\begin{array}{l}-0.096 \\
(-0.69)\end{array}$ & $\begin{array}{l}0.156 \\
(1.14)\end{array}$ & $\begin{array}{l}0.106 \\
(0.85)\end{array}$ \\
\hline$\Delta \mathrm{r}-10$ & $\begin{array}{l}0.111 \\
(0.58)\end{array}$ & $\begin{array}{l}-0.092 \\
(-0.36)\end{array}$ & $\begin{array}{l}0.059 \\
(0.36)\end{array}$ & $\begin{array}{l}-0.214 \\
(-2.65)\end{array}$ & $\begin{array}{l}-0.227 \\
(-2.87)\end{array}$ & $\begin{array}{l}-0.132 \\
(-1.85)\end{array}$ \\
\hline$(\Delta \mathrm{r}-10)^{\wedge} 2$ & $\begin{array}{l}0.174 \\
(0.57)\end{array}$ & $\begin{array}{l}0.076 \\
(0.18)\end{array}$ & $\begin{array}{l}0.037 \\
(0.14)\end{array}$ & $\begin{array}{l}-0.042 \\
(-0.33)\end{array}$ & $\begin{array}{l}-0.094 \\
(-0.75)\end{array}$ & $\begin{array}{l}-0.144 \\
(-1.26)\end{array}$ \\
\hline$\Delta \mathrm{S} \& \mathrm{P}$ & $\begin{array}{l}-0.443 \\
(-0.29)\end{array}$ & $\begin{array}{c}1.518 \\
(0.7)\end{array}$ & $\begin{array}{l}-0.757 \\
(-0.57)\end{array}$ & $\begin{array}{l}-1.622 \\
(-2.42)\end{array}$ & $\begin{array}{l}-0.580 \\
(-0.89)\end{array}$ & $\begin{array}{l}0.592 \\
(0.99)\end{array}$ \\
\hline$\Delta \mathrm{VIX}$ & $\begin{array}{c}-0.006 \\
(-0.5)\end{array}$ & $\begin{array}{l}0.004 \\
(0.23)\end{array}$ & $\begin{array}{l}-0.003 \\
(-0.29)\end{array}$ & $\begin{array}{l}0.003 \\
(0.56)\end{array}$ & $\begin{array}{l}0.002 \\
(0.41)\end{array}$ & $\begin{array}{l}0.006 \\
(1.26)\end{array}$ \\
\hline$\Delta$ Slope & $\begin{array}{l}-0.155 \\
(-0.74) \\
\end{array}$ & $\begin{array}{l}0.189 \\
(0.64)\end{array}$ & $\begin{array}{l}-0.039 \\
(-0.23) \\
\end{array}$ & $\begin{array}{l}0.298 \\
(3.29)\end{array}$ & $\begin{array}{l}0.269 \\
(3.02)\end{array}$ & $\begin{array}{l}0.075 \\
(0.92)\end{array}$ \\
\hline LIB-OIS F-test & $\begin{array}{c}20.16 \\
(<0.01) \\
\end{array}$ & $\begin{array}{c}10.26 \\
(<0.01) \\
\end{array}$ & $\begin{array}{c}26.13 \\
(<0.01) \\
\end{array}$ & $\begin{array}{c}2.99 \\
(0.08) \\
\end{array}$ & $\begin{array}{c}1.38 \\
(0.24) \\
\end{array}$ & $\begin{array}{c}1.08 \\
(0.30) \\
\end{array}$ \\
\hline ABX F-test & $\begin{array}{c}0.00 \\
(0.95) \\
\end{array}$ & $\begin{array}{c}0.73 \\
(0.40) \\
\end{array}$ & $\begin{array}{c}0.42 \\
(0.52) \\
\end{array}$ & $\begin{array}{c}0.00 \\
(0.95) \\
\end{array}$ & $\begin{array}{c}0.08 \\
(0.78) \\
\end{array}$ & $\begin{array}{r}0.39 \\
(0.59) \\
\end{array}$ \\
\hline
\end{tabular}




\begin{tabular}{|c|c|c|c|c|c|c|}
\hline & \multicolumn{6}{|c|}{ Panel B: Non-US Non-Subprime Asset Classes } \\
\hline & \multicolumn{6}{|c|}{$\begin{array}{c}\text { Credit Spreads } \\
\end{array}$} \\
\hline & \multirow{3}{*}{$\begin{array}{c}\text { Australia } \\
\text { RMBS }\end{array}$} & \multirow{3}{*}{\multicolumn{2}{|c|}{$\begin{array}{l}\text { Dutch } \\
\text { RMBS }\end{array}$}} & \multicolumn{3}{|c|}{ European } \\
\hline & & & & & Consumer & European \\
\hline & & & & UK Cards & Receivable & Auto \\
\hline \multirow[t]{2}{*}{ Intercept } & 0.014 & 0.017 & 0.014 & 0.031 & 0.032 & 0.037 \\
\hline & $(0.52)$ & $(0.93)$ & (1.14) & (2.4) & $(3.21)$ & $(2.35)$ \\
\hline \multirow[t]{2}{*}{$\Delta$ LIB-OIS } & 0.126 & 0.240 & 0.100 & 0.109 & 0.049 & 0.081 \\
\hline & (1.57) & (4.38) & (2.71) & (2.86) & (1.76) & $(1.8)$ \\
\hline \multirow{2}{*}{$\Delta$ LIB-OIS, $\mathrm{t}-1$} & 0.575 & 0.237 & 0.071 & 0.136 & 0.021 & 0.019 \\
\hline & $(7.56)$ & $(4.57)$ & $(2.11)$ & $(3.72)$ & $(0.8)$ & $(0.45)$ \\
\hline \multirow[t]{2}{*}{$\Delta \mathrm{LIB}-\mathrm{OIS}, \mathrm{t}-2$} & -0.181 & -0.051 & 0.115 & 0.019 & 0.033 & 0.104 \\
\hline & $(-2.44)$ & $(-1.01)$ & $(3.42)$ & $(0.52)$ & $(1.26)$ & $(2.51)$ \\
\hline \multirow{2}{*}{$\Delta$ LIB-OIS, t-3 } & 0.138 & 0.067 & -0.015 & -0.019 & 0.020 & 0.022 \\
\hline & $(1.86)$ & $(1.32)$ & $(-0.47)$ & $(-0.55)$ & $(0.77)$ & $(0.53)$ \\
\hline \multirow[t]{2}{*}{$\triangle \mathrm{ABX}$} & 0.025 & 0.029 & 0.095 & 0.094 & 0.116 & 0.095 \\
\hline & $(0.15)$ & $(0.26)$ & $(1.37)$ & $(1.03)$ & $(1.65)$ & $(0.84)$ \\
\hline \multirow[t]{2}{*}{$\Delta \mathrm{ABX}, \mathrm{t}-1$} & -0.002 & 0.022 & 0.002 & 0.028 & 0.001 & -0.010 \\
\hline & $(-0.02)$ & $(0.19)$ & $(0.03)$ & $(0.34)$ & $(0.01)$ & $(-0.09)$ \\
\hline \multirow[t]{2}{*}{$\triangle \mathrm{ABX}, \mathrm{t}-2$} & -0.171 & -0.018 & -0.037 & 0.011 & 0.037 & 0.044 \\
\hline & $(-1.09)$ & $(-0.17)$ & $(-0.54)$ & $(0.13)$ & $(0.54)$ & $(0.4)$ \\
\hline \multirow[t]{2}{*}{$\Delta \mathrm{ABX}, \mathrm{t}-3$} & 0.173 & 0.072 & -0.109 & -0.084 & -0.060 & -0.265 \\
\hline & (1.09) & $(0.66)$ & $(-1.6)$ & $(-1.05)$ & $(-0.9)$ & $(-2.47)$ \\
\hline \multirow[t]{2}{*}{$\Delta \mathrm{OIS}$} & 0.034 & -0.031 & -0.237 & -0.051 & -0.054 & -0.164 \\
\hline & $(0.1)$ & $(-0.15)$ & $(-0.63)$ & $(-0.33)$ & $(-0.48)$ & $(-0.91)$ \\
\hline \multirow[t]{2}{*}{$\Delta \mathrm{r}-10$} & -0.207 & -0.140 & -0.067 & -0.134 & -0.106 & -0.146 \\
\hline & $(-1.36)$ & $(-1.34)$ & $(-0.81)$ & $(-1.84)$ & $(-1.97)$ & $(-1.71)$ \\
\hline \multirow[t]{2}{*}{$(\Delta \mathrm{r}-10)^{\wedge} 2$} & 0.194 & -0.022 & -0.058 & -0.036 & -0.096 & -0.018 \\
\hline & $(0.85)$ & $(-0.15)$ & $(-0.5)$ & $(-0.34)$ & $(-1.23)$ & $(-0.15)$ \\
\hline \multirow[t]{2}{*}{$\Delta \mathrm{S} \& \mathrm{P}$} & -0.915 & -0.272 & -0.709 & 0.164 & 0.194 & 0.695 \\
\hline & $(-0.76)$ & $(-0.33)$ & $(-0.86)$ & $(0.28)$ & $(0.45)$ & $(1.01)$ \\
\hline \multirow[t]{2}{*}{$\Delta \mathrm{VIX}$} & -0.006 & -0.001 & -0.002 & 0.000 & 0.001 & 0.003 \\
\hline & $(-0.64)$ & $(-0.11)$ & $(-0.31)$ & $(0.07)$ & $(0.39)$ & $(0.6)$ \\
\hline \multirow[t]{2}{*}{$\Delta$ Slope } & 0.179 & 0.077 & 0.051 & 0.133 & 0.091 & 0.190 \\
\hline & $(1.05)$ & $(0.66)$ & $(0.51)$ & $(1.64)$ & $(1.53)$ & (2) \\
\hline LIB-OIS & 25.57 & 30.71 & 20.89 & 14.40 & 6.56 & 8.62 \\
\hline F-test & $(<0.01)$ & $(<0.01)$ & $(<0.01)$ & $(<0.01)$ & $(0.01)$ & $(<0.01)$ \\
\hline $\mathrm{ABX}$ & 0.01 & 0.28 & 0.14 & 0.09 & 0.51 & 0.41 \\
\hline F-test & $(0.93)$ & $(0.60)$ & $(0.71)$ & $(0.77)$ & $(0.48)$ & $(0.52)$ \\
\hline
\end{tabular}




\section{Table IV \\ Summary of F-Test Results for Different Asset Categories}

For each bond $i$, we estimate equation (2) using weekly data from January 4, 2007 to January 29, 2009, $\Delta$ LIB-OIS is the percentage change of the spread between the 3-month LIBOR and the Overnight Index Swap (OIS). This table summarizes the F-test results for the LIB-OIS state variable and its lags. The null hypothesis of F-test is the sum of all coefficients of $\triangle$ LIB-OIS and its lags is zero. The numbers in the table indicate how many F-tests of bonds in each category are significant at various confidence levels. Asset categories are listed in Panel A of Table I. "Negative" and "Positive" indicate the sign of the sum of coefficients for $\Delta$ LIB-OIS and its lags.

Panel A: Whole Period: January 4, 2007 to January 29, 2009

\begin{tabular}{cccccccc}
\hline & & \multicolumn{3}{c}{ Negative } & \multicolumn{3}{c}{ Positive } \\
\cline { 3 - 8 } Categories & Total Number & $10 \%$ & $5 \%$ & $1 \%$ & $10 \%$ & $5 \%$ & $1 \%$ \\
\hline Subprime & 63 & 1 & 1 & 0 & 2 & 1 & 2 \\
Nonsubprime_US & 176 & 3 & 0 & 0 & 4 & 7 & 106 \\
Nonsubprime_Europe & 59 & 0 & 0 & 0 & 0 & 6 & 39 \\
Financial & 46 & 0 & 0 & 0 & 3 & 2 & 6 \\
Industrial & 48 & 0 & 0 & 0 & 5 & 14 & 9 \\
\hline Total & 392 & 4 & 1 & 0 & 14 & 30 & 162 \\
\hline
\end{tabular}

Panel B: Subperiod I: January 4, 2007 to December 27, 2007

\begin{tabular}{|c|c|c|c|c|c|c|c|}
\hline \multirow[b]{2}{*}{ Categories } & \multirow[b]{2}{*}{ Total Number } & \multicolumn{3}{|c|}{ Negative } & \multicolumn{3}{|c|}{ Positive } \\
\hline & & $10 \%$ & $5 \%$ & $1 \%$ & $10 \%$ & $5 \%$ & $1 \%$ \\
\hline Subprime & 63 & 2 & 4 & 2 & 0 & 2 & 1 \\
\hline Nonsubprime_US & 176 & 4 & 0 & 1 & 8 & 21 & 75 \\
\hline Nonsubprime_Europe & 59 & 0 & 0 & 0 & 5 & 10 & 24 \\
\hline Financial & 46 & 3 & 1 & 0 & 1 & 2 & 1 \\
\hline Industrial & 48 & 0 & 0 & 0 & 0 & 1 & 4 \\
\hline Total & 392 & 9 & 5 & 3 & 14 & 36 & 105 \\
\hline \multicolumn{8}{|c|}{ Panel C: Subperiod II: January 3, 2008 to January 29,2009 } \\
\hline & & \multicolumn{3}{|c|}{ Negative } & \multicolumn{3}{|c|}{ Positive } \\
\hline Categories & Total Number & $10 \%$ & $5 \%$ & $1 \%$ & $10 \%$ & $5 \%$ & $1 \%$ \\
\hline Subprime & 63 & 1 & 0 & 0 & 0 & 0 & 0 \\
\hline Nonsubprime_US & 176 & 8 & 0 & 0 & 23 & 26 & 41 \\
\hline Nonsubprime_Europe & 59 & 0 & 0 & 0 & 0 & 1 & 0 \\
\hline Financial & 46 & 0 & 0 & 0 & 6 & 10 & 6 \\
\hline Industrial & 48 & 0 & 0 & 0 & 6 & 9 & 21 \\
\hline Total & 392 & 9 & 0 & 0 & 35 & 46 & 68 \\
\hline
\end{tabular}




\section{Table V \\ Summary of F-Test Results for Different Rating Classes}

For each bond $i$, we estimate equation (2) using weekly data from January 4, 2007 to January 29, 2009, $\Delta$ LIB-OIS is the percentage change of the spread between the 3-month LIBOR and the Overnight Index Swap (OIS).This table summarizes the F-test results for the LIB-OIS state variable and its lags. The null hypothesis of F-test is the sum of all coefficients of $\Delta$ LIB-OIS and its lags is zero. The numbers in the table indicate how many F-tests of bonds in each rating class are significant at various confidence levels. "Negative" and "Positive" indicate the sign of the sum of the coefficients for $\triangle$ LIB-OIS and its lags.

Panel A: Whole Period: January 4, 2007 to January 29, 2009

\begin{tabular}{|c|c|c|c|c|c|c|c|}
\hline \multirow[b]{2}{*}{ Rating } & \multirow[b]{2}{*}{ Total Number } & \multicolumn{3}{|c|}{ Negative } & \multicolumn{3}{|c|}{ Positive } \\
\hline & & $10 \%$ & $5 \%$ & $1 \%$ & $10 \%$ & $5 \%$ & $1 \%$ \\
\hline $\mathrm{AAA}$ & 157 & 4 & 0 & 0 & 4 & 10 & 83 \\
\hline AA & 47 & 0 & 1 & 0 & 1 & 3 & 9 \\
\hline A & 74 & 0 & 0 & 0 & 3 & 5 & 33 \\
\hline BBB & 83 & 0 & 0 & 0 & 2 & 6 & 36 \\
\hline Other & 31 & 0 & 0 & 0 & 4 & 6 & 1 \\
\hline Total & 392 & 4 & 1 & 0 & 14 & 30 & 162 \\
\hline \multicolumn{8}{|c|}{ Panel B: Subperiod I: January 4, 2007 to December 27, 2007} \\
\hline & & \multicolumn{3}{|c|}{ Negative } & \multicolumn{3}{|c|}{ Positive } \\
\hline Rating & Total Number & $10 \%$ & $5 \%$ & $1 \%$ & $10 \%$ & $5 \%$ & $1 \%$ \\
\hline AAA & 157 & 5 & 1 & 1 & 9 & 25 & 47 \\
\hline AA & 47 & 0 & 0 & 1 & 0 & 1 & 7 \\
\hline A & 74 & 0 & 2 & 0 & 3 & 4 & 27 \\
\hline BBB & 83 & 1 & 1 & 0 & 1 & 5 & 23 \\
\hline Other & 31 & 3 & 1 & 1 & 1 & 1 & 1 \\
\hline Total & 392 & 9 & 5 & 3 & 14 & 36 & 105 \\
\hline \multicolumn{8}{|c|}{ Panel C: Subperiod II: January 3, 2008 to January 29,2 009} \\
\hline & & \multicolumn{3}{|c|}{ Negative } & \multicolumn{3}{|c|}{ Positive } \\
\hline Rating & Total Number & $10 \%$ & $5 \%$ & $1 \%$ & $10 \%$ & $5 \%$ & $1 \%$ \\
\hline AAA & 157 & 0 & 0 & 0 & 4 & 13 & 44 \\
\hline AA & 47 & 1 & 0 & 0 & 3 & 12 & 4 \\
\hline A & 74 & 4 & 0 & 0 & 14 & 9 & 5 \\
\hline BBB & 83 & 4 & 0 & 0 & 9 & 11 & 5 \\
\hline Other & 31 & 0 & 0 & 0 & 5 & 1 & 10 \\
\hline Total & 392 & 9 & 0 & 0 & 35 & 46 & 68 \\
\hline
\end{tabular}




\section{Table VI \\ Repo Spreads Regression Results}

For each class of securitized bonds, we estimate equation (3) using weekly data from January 4, 2007 to January 29, 2009. $\triangle$ LIB-OIS is the percentage change of the spread between the 3-month LIBOR and the Overnight Index Swap (OIS). $\triangle \mathrm{ABX}$ is the parentage change of the $\mathrm{ABX}$ index at period t. $\Delta \mathrm{OIS}$ is the Overnight Index Swap. $\Delta \mathrm{r}-10$ is the change in yield on the 10-year Treasury, with its square given by $(\Delta \mathrm{r}-10)^{\wedge} 2 . \Delta$ Slope is the change in 10 -year minus 2 -year Treasury yields. $\Delta$ VIX is the change in implied volatility of S\&P 500, and $\Delta$ S\&P is the return on S\&P 500. tstatistics are given in parentheses below the coefficient estimates. The last two rows report F-statistics and p-values for the key state variables. The null hypothesis of the LIB-OIS F-Test is that the sum of all coefficients of $\Delta$ LIB-OIS and its lags is zero. The null hypothesis of the ABX F-Test is the sum of all coefficients of $\triangle \mathrm{ABX}$ and its lags is zero. The null hypothesis of the VOL F-Test is the sum of all coefficients of VOL and its lags is zero.

\begin{tabular}{|c|c|c|c|c|c|}
\hline & \multicolumn{5}{|c|}{ Repo Rate Spreads } \\
\hline & $\begin{array}{l}\text { A-AAA ABS- } \\
\text { Auto / CC / SL }\end{array}$ & $\begin{array}{c}<\text { AA ABS- } \\
\text { RMBS / CMBS }\end{array}$ & $\begin{array}{l}\text { AA-AAA ABS- } \\
\text { RMBS / CMBS }\end{array}$ & AA-AAA CLO & AA-AAA CDO \\
\hline \multirow[t]{2}{*}{ Intercept } & 0.035 & 0.015 & 0.016 & 0.017 & 0.024 \\
\hline & $(0.86)$ & $(0.89)$ & $(0.71)$ & $(0.71)$ & $(0.93)$ \\
\hline \multirow[t]{2}{*}{$\Delta$ LIB-OIS } & 1.321 & 0.825 & 1.043 & 1.025 & 0.558 \\
\hline & $(12)$ & $(17.26)$ & $(16.45)$ & $(15.66)$ & $(7.26)$ \\
\hline \multirow[t]{2}{*}{$\Delta$ LIB-OIS, t-1 } & -0.168 & -0.004 & -0.056 & -0.068 & 0.044 \\
\hline & $(-1.58)$ & $(-0.1)$ & $(-0.93)$ & $(-1.08)$ & $(0.67)$ \\
\hline \multirow[t]{2}{*}{$\Delta$ LIB-OIS, t-2 } & 0.084 & 0.071 & 0.099 & 0.115 & 0.062 \\
\hline & $(0.8)$ & $(1.57)$ & (1.65) & $(1.85)$ & $(0.85)$ \\
\hline \multirow[t]{2}{*}{$\Delta$ LIB-OIS, t-3 } & -0.134 & 0.004 & -0.040 & -0.021 & 0.010 \\
\hline & $(-1.27)$ & $(0.09)$ & $(-0.66)$ & $(-0.35)$ & $(0.15)$ \\
\hline \multirow[t]{2}{*}{$\triangle \mathrm{ABX}$} & -0.188 & -0.152 & -0.169 & -0.183 & -0.031 \\
\hline & $(-0.86)$ & $(-1.59)$ & $(-1.32)$ & $(-1.4)$ & $(-0.23)$ \\
\hline \multirow[t]{2}{*}{$\triangle \mathrm{ABX}, \mathrm{t}-1$} & 0.227 & 0.020 & 0.072 & 0.076 & 0.206 \\
\hline & $(1.03)$ & $(0.21)$ & $(0.57)$ & $(0.58)$ & $(1.5)$ \\
\hline \multirow[t]{2}{*}{$\triangle \mathrm{ABX}, \mathrm{t}-2$} & 0.435 & 0.007 & 0.092 & 0.086 & 0.037 \\
\hline & (1.99) & $(0.07)$ & $(0.73)$ & $(0.66)$ & $(0.28)$ \\
\hline \multirow[t]{2}{*}{$\triangle \mathrm{ABX}, \mathrm{t}-3$} & 0.018 & 0.064 & 0.057 & 0.085 & 0.052 \\
\hline & $(0.08)$ & $(0.67)$ & $(0.44)$ & $(0.66)$ & $(0.38)$ \\
\hline \multirow[t]{2}{*}{$\Delta \mathrm{VOL}$} & -0.002 & 0.000 & 0.000 & 0.000 & 0.000 \\
\hline & $(-0.32)$ & $(0.15)$ & $(0.42)$ & $(0.25)$ & $(0.25)$ \\
\hline \multirow[t]{2}{*}{$\Delta \mathrm{VOL}, \mathrm{t}-1$} & 0.000 & 0.000 & -0.001 & -0.001 & -0.002 \\
\hline & $(0.03)$ & $(-0.35)$ & $(-0.73)$ & $(-0.6)$ & $(-0.84)$ \\
\hline \multirow[t]{2}{*}{$\Delta \mathrm{VOL}, \mathrm{t}-2$} & -0.002 & 0.000 & 0.001 & 0.001 & 0.001 \\
\hline & $(-0.32)$ & $(0.76)$ & $(0.98)$ & $(0.45)$ & $(0.26)$ \\
\hline \multirow[t]{2}{*}{$\Delta \mathrm{VOL}, \mathrm{t}-3$} & 0.001 & 0.000 & -0.001 & -0.001 & 0.002 \\
\hline & $(0.18)$ & $(-0.78)$ & $(-1.19)$ & $(-1.3)$ & $(0.8)$ \\
\hline \multirow[t]{2}{*}{$\Delta \mathrm{OIS}$} & 0.060 & -0.044 & -0.078 & -0.005 & 0.184 \\
\hline & $(0.11)$ & $(-0.19)$ & $(-0.21)$ & $(-0.01)$ & $(0.21)$ \\
\hline \multirow[t]{2}{*}{$\Delta \mathrm{r}-10$} & 0.085 & 0.023 & 0.085 & 0.028 & 0.142 \\
\hline & $(0.4)$ & $(0.27)$ & $(0.73)$ & $(0.23)$ & $(0.79)$ \\
\hline \multirow[t]{2}{*}{$(\Delta \mathrm{r}-10)^{\wedge} 2$} & -0.178 & -0.019 & 0.010 & 0.019 & -0.082 \\
\hline & $(-0.52)$ & $(-0.13)$ & $(0.05)$ & (0.09) & $(-0.35)$ \\
\hline \multirow[t]{2}{*}{$\Delta \mathrm{S} \& \mathrm{P}$} & -0.374 & 0.136 & -0.158 & 0.430 & -2.373 \\
\hline & $(-0.21)$ & $(0.17)$ & $(-0.15)$ & (0.39) & $(-1.38)$ \\
\hline \multirow[t]{2}{*}{$\Delta \mathrm{VIX}$} & 0.004 & 0.000 & 0.001 & 0.006 & 0.000 \\
\hline & $(0.29)$ & $(-0.01)$ & $(0.09)$ & $(0.64)$ & $(-0.01)$ \\
\hline \multirow[t]{2}{*}{$\Delta$ Slope } & -0.218 & -0.080 & -0.122 & -0.027 & -0.196 \\
\hline & $(-0.98)$ & $(-0.81)$ & $(-0.92)$ & $(-0.2)$ & $(-0.99)$ \\
\hline \multirow{2}{*}{ LIB-OIS F-Test } & 32.56 & 129.61 & 100.87 & 96.07 & 30.37 \\
\hline & $(<0.01)$ & $(<0.01)$ & $(<0.01)$ & $(<0.01)$ & $(<0.01)$ \\
\hline \multirow{2}{*}{ ABX F-Test } & 1.44 & 0.12 & 0.05 & 0.07 & 1.07 \\
\hline & $(0.23)$ & $(0.73)$ & $(0.82)$ & $(0.79)$ & $(0.3)$ \\
\hline \multirow{2}{*}{ VOL F-Test } & 0.53 & 0.01 & 0.34 & 1.80 & 0.14 \\
\hline & $(0.47)$ & $(0.93)$ & $(0.56)$ & $(0.18)$ & $(0.71)$ \\
\hline
\end{tabular}




\section{Table VII \\ Haircut Regression Results}

For each class of securitized bonds, we estimate equation (7) using weekly data from January 4, 2007 to January 29, 2009, $\triangle$ LIB-OIS is the percentage change of the spread between the 3-month LIBOR and the Overnight Index Swap (OIS). $\triangle \mathrm{ABX}$ is the parentage change of the $\mathrm{ABX}$ index at period t. $\triangle \mathrm{OIS}$ is the Overnight Index Swap. $\Delta \mathrm{r}-10$ is the change in yield on the 10-year Treasury, with its square given by $(\Delta \mathrm{r}-10)^{\wedge} 2 . \Delta$ Slope is the change in 10 -year minus 2 -year Treasury yields. $\Delta$ VIX is the change in implied volatility of S\&P 500, and $\Delta$ S\&P is the return on S\&P 500. tstatistics are given in parentheses below the coefficient estimates. The last two rows report F-statistics and p-values for the key state variables. The null hypothesis of the LIB-OIS F-Test is that the sum of all coefficients of $\Delta$ LIB-OIS and its lags is zero. The null hypothesis of the ABX F-Test is the sum of all coefficients of $\triangle \mathrm{ABX}$ and its lags is zero. The null hypothesis of the VOL F-Test is the sum of all coefficients of VOL and its lags is zero.

\begin{tabular}{|c|c|c|c|c|c|}
\hline \multicolumn{6}{|c|}{ Haircut Regression with Lags } \\
\hline & \multicolumn{5}{|c|}{ Change of Haircuts } \\
\hline & $\begin{array}{l}\text { A-AAA ABS- } \\
\text { Auto / CC / SL }\end{array}$ & $\begin{array}{c}<\text { AA ABS- } \\
\text { RMBS / CMBS }\end{array}$ & $\begin{array}{l}\text { AA-AAA ABS- } \\
\text { RMBS / CMBS }\end{array}$ & AA-AAA CDO & AA-AAA CLO \\
\hline Intercept & $\begin{array}{c}0.00096 \\
(0.69)\end{array}$ & $\begin{array}{c}0.00266 \\
(1.19)\end{array}$ & $\begin{array}{c}0.00194 \\
(1.08)\end{array}$ & $\begin{array}{c}-0.00514 \\
(-0.34)\end{array}$ & $\begin{array}{c}0.00311 \\
(1.59)\end{array}$ \\
\hline$\Delta \mathrm{LIB}-\mathrm{OIS}$ & $\begin{array}{c}-0.00010 \\
(-1.44)\end{array}$ & $\begin{array}{c}0.00009 \\
(0.89)\end{array}$ & $\begin{array}{c}0.00010 \\
(1.25)\end{array}$ & $\begin{array}{c}0.00121 \\
(0.85)\end{array}$ & $\begin{array}{c}0.00003 \\
(0.27)\end{array}$ \\
\hline$\Delta \mathrm{LIB}-\mathrm{OIS}, \mathrm{t}-1$ & $\begin{array}{c}-0.00010 \\
(-1.53)\end{array}$ & $\begin{array}{c}0.00001 \\
(0.07)\end{array}$ & $\begin{array}{c}-0.00002 \\
(-0.24)\end{array}$ & $\begin{array}{c}0.00079 \\
(0.55)\end{array}$ & $\begin{array}{c}0.00008 \\
(0.67)\end{array}$ \\
\hline$\Delta$ LIB-OIS, t-2 & $\begin{array}{c}0.00005 \\
(0.75)\end{array}$ & $\begin{array}{c}0.00008 \\
(0.75)\end{array}$ & $\begin{array}{c}0.00011 \\
(1.31)\end{array}$ & $\begin{array}{c}-0.00053 \\
(-0.41)\end{array}$ & $\begin{array}{c}-0.00016 \\
(-1.45)\end{array}$ \\
\hline$\Delta$ LIB-OIS, t-3 & $\begin{array}{c}-0.00001 \\
(-0.12)\end{array}$ & $\begin{array}{c}-0.00014 \\
(-1.2)\end{array}$ & $\begin{array}{c}-0.00010 \\
(-1.18)\end{array}$ & $\begin{array}{c}0.00073 \\
(0.62)\end{array}$ & $\begin{array}{c}0.00006 \\
(0.74)\end{array}$ \\
\hline$\triangle \mathrm{ABX}$ & $\begin{array}{c}0.00001 \\
(1.05)\end{array}$ & $\begin{array}{c}0.00000 \\
(0.33)\end{array}$ & $\begin{array}{c}0.00001 \\
(1.19)\end{array}$ & $\begin{array}{c}0.00004 \\
(0.69)\end{array}$ & $\begin{array}{c}0.00000 \\
(-0.34)\end{array}$ \\
\hline$\triangle \mathrm{ABX}, \mathrm{t}-1$ & $\begin{array}{c}0.00000 \\
(0.06)\end{array}$ & $\begin{array}{c}-0.00001 \\
(-1.05)\end{array}$ & $\begin{array}{c}0.00000 \\
(-0.64)\end{array}$ & $\begin{array}{c}0.00001 \\
(0.2)\end{array}$ & $\begin{array}{c}0.00000 \\
(0.18)\end{array}$ \\
\hline$\triangle \mathrm{ABX}, \mathrm{t}-2$ & $\begin{array}{c}0.00000 \\
(0.12)\end{array}$ & $\begin{array}{c}0.00001 \\
(0.67)\end{array}$ & $\begin{array}{c}0.00001 \\
(0.86)\end{array}$ & $\begin{array}{c}0.00002 \\
(0.32)\end{array}$ & $\begin{array}{c}0.00000 \\
(0.43)\end{array}$ \\
\hline$\triangle \mathrm{ABX}, \mathrm{t}-3$ & $\begin{array}{c}0.00000 \\
(-0.79)\end{array}$ & $\begin{array}{c}-0.00001 \\
(-1.4)\end{array}$ & $\begin{array}{c}-0.00001 \\
(-1.58)\end{array}$ & $\begin{array}{c}0.00003 \\
(0.44)\end{array}$ & $\begin{array}{c}-0.00001 \\
(-1.34)\end{array}$ \\
\hline$\Delta \mathrm{VOL}$ & $\begin{array}{c}0.00036 \\
(2.31)\end{array}$ & $\begin{array}{c}0.00001 \\
(0.52)\end{array}$ & $\begin{array}{c}0.00000 \\
(-0.06)\end{array}$ & $\begin{array}{c}0.00311 \\
(3.19)\end{array}$ & $\begin{array}{c}0.00015 \\
(2.05)\end{array}$ \\
\hline$\Delta \mathrm{VOL}, \mathrm{t}-1$ & $\begin{array}{c}-0.00049 \\
(-2.01)\end{array}$ & $\begin{array}{c}-0.00001 \\
(-0.24)\end{array}$ & $\begin{array}{c}-0.00001 \\
(-0.12)\end{array}$ & $\begin{array}{c}-0.00345 \\
(-2.37)\end{array}$ & $\begin{array}{c}0.00000 \\
(0.04)\end{array}$ \\
\hline$\Delta \mathrm{VOL}, \mathrm{t}-2$ & $\begin{array}{c}0.00049 \\
(2.09)\end{array}$ & $\begin{array}{c}0.00002 \\
(0.36)\end{array}$ & $\begin{array}{c}0.00003 \\
(0.34)\end{array}$ & $\begin{array}{c}0.00235 \\
(1.57)\end{array}$ & $\begin{array}{c}-0.00016 \\
(-1.61)\end{array}$ \\
\hline$\Delta \mathrm{VOL}, \mathrm{t}-3$ & $\begin{array}{c}-0.00005 \\
(-0.28)\end{array}$ & $\begin{array}{c}-0.00001 \\
(-0.52)\end{array}$ & $\begin{array}{c}-0.00004 \\
(-0.69)\end{array}$ & $\begin{array}{c}0.00006 \\
(0.05)\end{array}$ & $\begin{array}{c}0.00017 \\
(1.99)\end{array}$ \\
\hline$\Delta \mathrm{OIS}$ & $\begin{array}{c}0.00476 \\
(0.4)\end{array}$ & $\begin{array}{c}-0.01801 \\
(-0.92)\end{array}$ & $\begin{array}{c}-0.01655 \\
(-1.02)\end{array}$ & $\begin{array}{c}-0.09061 \\
(-0.67)\end{array}$ & $\begin{array}{c}-0.01967 \\
(-1.2)\end{array}$ \\
\hline$\Delta \mathrm{r}-10$ & $\begin{array}{c}0.00413 \\
(0.6)\end{array}$ & $\begin{array}{c}-0.01072 \\
(-1.02)\end{array}$ & $\begin{array}{c}-0.00689 \\
(-0.82)\end{array}$ & $\begin{array}{c}0.04610 \\
(0.51)\end{array}$ & $\begin{array}{c}0.00241 \\
(0.26)\end{array}$ \\
\hline$(\Delta \mathrm{r}-10)^{\wedge} 2$ & $\begin{array}{c}0.00703 \\
(0.64)\end{array}$ & $\begin{array}{c}-0.00617 \\
(-0.36)\end{array}$ & $\begin{array}{c}-0.00882 \\
(-0.62)\end{array}$ & $\begin{array}{c}-0.13209 \\
(-0.97)\end{array}$ & $\begin{array}{c}-0.00100 \\
(-0.06)\end{array}$ \\
\hline$\Delta \mathrm{S} \& \mathrm{P}$ & $\begin{array}{c}0.03663 \\
(0.66)\end{array}$ & $\begin{array}{c}-0.02488 \\
(-0.28)\end{array}$ & $\begin{array}{c}-0.06200 \\
(-0.89)\end{array}$ & $\begin{array}{c}0.07360 \\
(0.09)\end{array}$ & $\begin{array}{c}-0.00699 \\
(-0.09)\end{array}$ \\
\hline$\Delta \mathrm{VIX}$ & $\begin{array}{c}0.00037 \\
(0.77)\end{array}$ & $\begin{array}{c}-0.00014 \\
(-0.18)\end{array}$ & $\begin{array}{c}-0.00042 \\
(-0.68)\end{array}$ & $\begin{array}{c}0.00098 \\
(0.14)\end{array}$ & $\begin{array}{c}-0.00074 \\
(-1.07)\end{array}$ \\
\hline$\Delta$ Slope & $\begin{array}{c}0.01253 \\
(1.63)\end{array}$ & $\begin{array}{c}0.01069 \\
(0.85)\end{array}$ & $\begin{array}{c}0.00682 \\
(0.67)\end{array}$ & $\begin{array}{c}-0.07066 \\
(-0.7)\end{array}$ & $\begin{array}{c}-0.00906 \\
(-0.85)\end{array}$ \\
\hline LIB-OIS F-Test & $\begin{array}{c}1.47 \\
(0.23)\end{array}$ & $\begin{array}{c}0.06 \\
(0.81)\end{array}$ & $\begin{array}{c}0.69 \\
(0.41)\end{array}$ & $\begin{array}{c}0.89 \\
(0.35)\end{array}$ & $\begin{array}{c}0.01 \\
(0.91)\end{array}$ \\
\hline ABX F-Test & $\begin{array}{c}0.05 \\
(0.83) \\
\end{array}$ & $\begin{array}{c}0.58 \\
(0.45) \\
\end{array}$ & $\begin{array}{c}0.01 \\
(0.92) \\
\end{array}$ & $\begin{array}{c}0.64 \\
(0.43) \\
\end{array}$ & $\begin{array}{c}0.32 \\
(0.57) \\
\end{array}$ \\
\hline VOL F-Test & $\begin{array}{c}4.66 \\
(0.03)\end{array}$ & $\begin{array}{c}0.07 \\
(0.80)\end{array}$ & $\begin{array}{c}0.29 \\
(0.60)\end{array}$ & $\begin{array}{c}5.33 \\
(0.02)\end{array}$ & $\begin{array}{c}5.53 \\
(0.02)\end{array}$ \\
\hline
\end{tabular}


